\title{
VERBOS LOCALES ESTATIVOS EN ESPAÑOL
}

\author{
José Luis Cifuentes Honirubia \\ Universidad de Alicante \\ Cifu@ua.es
}

\begin{abstract}
Resumen
This paper deals with a typology of local stative verbs in Spanish. This classification is due to the constructions in which the verbs appear and it is similar to the one established for motion verbs. Thus, I distinguish between situative verbs, position verbs with local incorporation. Situative verbs are those which point out the place where the action is developed. Position verbs determine localization and the way in which a stance is articulated, and they can be classificd following parameters such as contacl, sensation and physical stance. Finally, I discuss those verbs which have the local component (ground, figure or relational particle) incorporated.
\end{abstract}

\section{INTRODUCCIÓN}

Los objetivos de este trabajo son los de proponer una tipología de los verbos locales estativos para el español, es decir, de los verbos posibilitados por las construcciones de lugar en dónde, o ubi. Empezaremos distinguiendo un primer grupo, los situativos, que pueden construirse bien como transitivos bien como intransitivos, analizando para ello la importancia quc puede tener el elemento agentivo. Después, y particndo de la estructura local conceptual de Talmy, y de forma semcjante a los verbos de desplazamiento, distinguiremos un grupo de verbos, los de manera de posición, que, además de indicar localización en dónde, señalan una determinada postura de la figura, diferenciando distintos subtipos o posibilidades en su interior. Y, por último, describiremos el grupo de verbos que pueden ser analizados como resultado de un proceso de incorporación local, sea de la base, de la figura o del rclacionante.

\subsection{Verbos locales estativos}

Para cllo debemos partir de algunos presupuestos que es ncecsario aclarar mínimamente antes de realizar tal propuesta descriptiva y que conciernen, fundamentalmente, al sintagma verbos locales estativos. A pesar de que hable y clasifique verbos, en realidad no estoy operando con una forma global sino con un significado. Quiero decir con ello que, cuando trato o clasifico un verbo, no lo considero en su totalidad, sino en el significado que me interesa,

1 El presente trabajo forma parte del proyecto de investigación «Verbos de estado en español: modelos cognitivos y procesos de estructuración categorial», financiado por el que fue Ministerio de Ciencia y Tecnología, referencia BFF2002-02442. 
desconsiderando, evidentemente, todos aquellos otros significados (con las estructuras sintácticas que puedan implicar) quc pudiera tener. Así, por ejemplo, si hablo del vcrbo acostar como verbo local estativo me estoy refiriendo a la construcción (o esquema predicactancial) que posibilita con el significado «echar o tender a uno para que descanse, esp. cn la cama», resultando totalmente indiferentes las construcciones posibilitadas por otros significados como «llegar a la costa», «inclinarse hacia un lado», etc.

\subsection{Verbos locales y localizables}

Aclarado, pues, que no me estoy refiriendo al vcrbo en su conjunto, sino al verbo en su significado local estativo, dado por el tipo de complemento con el que se combina, se hace necesario aclarar qué significo con los dos términos restantes. Cuando hablo de verbos locales me refiero a verbos, o construcciones posibilitadas por un tipo de significado verbal, con un complemento de lugar exigido de forma obligatoria. De nuevo son dos las aclaraciones que me veo obligado a hacer: qué es un lugar, y qué quiero decir con que ese lugar venga exigido de forma obligatoria para la construcción. Empezaré por el final: la obligatoriedad sintáctica y semántica como criterio delimitador de la actancialidad funcional ha sido muy debatida, y no voy a recordar nada al respecto, lo que sí está claro es que no se puede trazar una frontera neta entre obligatorio y accesorio on el plano sintáctico y semántico. En ese sentido, únicamente quiero aclarar que consideraré obligatorias construcciones locales como las siguientes ${ }^{2}$. 1) reside en Mutxamel: entiendo que este lipo de construcciones supone un complemento de lugar obligatorio porque el verbo residir, con el significado intuible anteriormentc, muy difícilmente va a posibilitar alguna construcción en la que no aparezca una localización, y, en cualquier caso, el esquema mental ${ }^{3}$ que supone el vorbo con ese significado obliga a la consideración de una localización. De igual forma, construcciones como 2) pon el libro en la mesa, también conllevarán la consideración de un complemento de lugar obligatorio. Es cierto que, en algún caso, las circunstancias enunciativas pueden haccr que no aparezca explícita la localización (- ¿Pongo el hibro en la mesa?, -No, no lo pongas), pero, al igual que en el caso anterior, el esquema mental que supone el verbo con esc significado obliga a la consideración de una localización. Más dificil de justificar pueden resultar casos como los siguientes:

\section{Empleó a su hijo en un ministerio. \\ Permaneció en su sitio. \\ Reinó sobre muchos pueblos. \\ Resiableció la monarquía en España.}

Creo que, a priori, podría resultar fácil criticar las anteriores construcciones por su valor local, pues es posible emplear a alguien en algo sin considerar el lugar. El significado concreto del verbo que estamos utilizando es el siguiente: «ocupar [a uno] encargándole un trabajo, negocio o comisión; esp. destinar [a uno] al servicio público». Es decir, el verbo emplear, con el significado considerado, aparte de un agente y un tema, necesita de una

2 Vid. E. Ramón Trives (1990) y (2001) para una fundamentación de la diferencia entre local y localizable.

3 Para lo que quiero significar con esquema mental remito al lector interesado a cualquier introducción a la lingüistica cognitiva. Asi, en español, resultan adecuadas las de Cifientes (1994) o Cuenca y Hilferty (1999). 
actividad en la que emplear ese tema, pudiendo estar esa actividad incluso dada contextualmente:

\author{
- ¿Has contratado ya a alguien? \\ -No, no he empleado a nadie todavia.
}

En este último ejemplo, la actividad viene dada contextualmente por el conocimiento compartido de los dos interlocutores, $y$, si bien puede no estar explícito lingüisticamente, en el esquema que comparten ambos participantes está funcionalmente presente. Ahora bien, la actividad de la que vengo hablando puede manifestarse sintácticamente de diversas maneras: la ha empleado de asistenta, la ha empleado limpiando la casa, la ha empleado en la caja, etc., y una de esas maneras es mediantc un complemento de lugar, pues a través del lugar puede venir implicada la actividad: si alguien trabaja en la caja, es claro que la actividad que desarrolla es de cajera.

El segundo de los ejemplos no es exactamente igual al anterior. Estamos utilizando el verbo permanecer con el significado de «mantenerse sin mutación en un mismo lugar, estado o calidad». Así, es posible encontrar ejemplos como permaneció mudo en todo momento, permaneció atado a la mesa durante horas, permaneció en su puesto durante el ataque. La construcción con permanecer requiere obligatoriamente un experimentante y un estado, pudiendo ser un estado local. Es decir, es posible permanecer mudo o permanecer en su puesto, mudo y en su puesto supondrían casillas excluyentes del verbo permanecer, puesto que de cualquiera de esas maneras (u otras) se completa la acción de «mantenerse sin mutación». Es por ello que si nos encontramos con la construcción permaneció mudo en casa de sus suegros, el sintagma en casa de sus suegros no tendría el mismo valor que los antcriores, evidentemente, puesto que sería una localización adjunta, y por ello circunstancial.

El caso de reinar es parecido. Estoy considerándolo con los significados de «regir un rey o príncipe un estado. Dominar o tener predominio una persona o cosa sobre otras». De csta forma, junto a casos característicos como reinó en España durante 25 años, puede haber ejemplos que, aparentemente, no supongan una concepción local, como reinó sobre muchos pueblos. En este último ejemplo es claro que hay una relación metonímica entre un lugar y los habilantes de ese lugar, por lo que puede ocurrir que, aparentemente, haya posibilidad en la construcción de no manifestar complemento de lugar, pero la relación metonímica nos explica el comportamiento sintáctico, pues la localización siempre estará presente en la construcción, aunque puede haber muchos casos en que ésta venga dada de otra manera, mcdiante otra conceptualización.

El último de los cjcmplos es más complicado de justificar. Estoy utilizando el verbo restablecer con el significado de «volver a establecer [una cosa]; ponerla en el estado que antes tenía». No pretendo decir que la necesidad de la localización de la construcción viene dada por la relación con el verbo establecer, para el cual la localización es necesaria, pues creo que precisamente lo que se conceptualiza con esta construcción es el hecho de «volver $a$ establecers, no tanto la localización patente con establecer. Pero enticndo que con esta construcción existe siempre una localización implicada, lo que ocurre es que, en muchísimas ocasiones, viene dada por la localización del tema objeto del restablecimiento: si digo hoy que restablecer la paz, la localización del ámbito de afectación del restablecimicnto de la paz es necesaria, ahora bien, será normalmente conocida por los interlocutores, lo que 
hace inútil su aparición: hay que restablecer la paz (en Iraq). Si estoy hablando de Iraq, resulta totalmentc innecesario volver a indicar el ámbito de localización de la construcción con restablecer. Sólo será necesario indicarlo cuando resulte desconocida o nueva para el interlocutor, pero entiendo que siempre es necesaria, puesto que no se puede restablecer la paz o la monarquía o cualquier otra cosa, si no es en algún sitio. Es decir, el lugar está implicado obligatoriamente en el esquema mental de la construcción. Le confiero, por ello, un valor actancial, no circunstancial, como pudiera tener una localización en la construcción ¿has comido ya? Evidentemente cuando comemos lo hacemos en algún hugar, pero podemos concebir la idea de comer sin su localización, por el hecho en si de comer. Ahora bien, restablecer algo siempre supone un ámbito local de aplicación.

Lo que he pretendido demostrar con estos ejemplos es que la necesidad del complemento de lugar no siempre es la misma, pero en todos los casos entiendo que cs necesaria una localización para el esquema mental del desarrollo de la acción, o del estado, dado por la construcción. Y es por csa razón por la que hablo de verbos locales: verbos que, en las construcciones consideradas, requieren un complemento de lugar.

\subsection{Complemento de lugar}

Falta por considerar qué cnticndo por complemento de lugar, es decit, qué es un lugar, ya que lo que es un complemento no lo voy a comentar. Un complemento de lugar es ralgo» que desarrolla una función de localización, pero, como hemos señalado en repetidas ocasiones (Cifuentes, 1989; Cifuentes y Llopis, 1996), en las lenguas históricas, un lugar sólo puede ser escogido o señalado fijándolo en relación a otro lugar. Quiero decir con ello que la caracteristica fundamental de la estructura semántica de la localización espacial es que, lingüísticamente, un lugar no puede venir identificado por sí mismo, sino que siempre debe serlo en relación a un objeto (Parisi-Castclfranchi, 1970). Así pues, la configuración espacial en la lengua viene usada principalmente para indicar dónde están las cosas, siendo esa indicación, frecuentemente, un importantísimo aspecto de la identificación o referencia (Millar y Johnson-Laird, 1976; 410).

Así pues, todo objeto está situado en relación a un lugar, concreto, mental o imaginario, $y$, recíprocamente, todo lugar es susceptible de ser ocupado por un objeto o N objetos. Perceptivamente el objeto localizante es fondo o base que posibilita la localización del objeto localizado o figura. Así, en el ejemplo Cristina vive en Alicante, "Cristina» es el objeto localizado o figura, mientras que «Alicante» es el objeto localizante o base, señalando el elemento de relación ken», la vinculación espacial (interioridad) existente entrc ambos y propiciada por el relator verbal. Y al hablar de rclaciones espaciales no sólo debemos considerar el lugar quc ocupa determinado objeto, sino también las relaciones que se establecen entre los lugares por medio de una región espacial que contiene cl lugar de un objeto. Para poder hablar de región espacial es neccsario que exista una interacción entre los dos objetos (figura y base) y entre ellos y el sujeto (Millar y Johnson-Laird, 1976: 59).

Tenemos, pues, el lugar como aquello que cstablece una disjunción en el espacio, y el elemento que puedc establecer tal disjunción es un objeto, que, como elemento discreto, separa y une -por su interacción- distancias y lugares. Así pucs, al localizar la figura en relación a la base, tenemos un objeto primero que se localiza en relación a un objeto segundo, y teniendo en cuenta la amplia o vaga concepción que de objeto tenemos, este objeto 
puede ser cualquier cosa que marca una separación en el espacio. Estas consideraciones son importantes, porque debemos tener en cuenta que, sobre todo en la base, hay una frecuente identificación entre el objeto en cuanto tal entidad y el lugar que ocupa; cs decir, la esencia de todo objeto es que ocupa un lugar, y sus disposiciones con el resto del entorno serán las características fundamentales que se consideren en la localización. Estas ideas son las que nos permiten fundamentar complementos de lugar tan diversos como en Marte hay agua o hallamos insectos en su caheza, al igual que pretendc justificar construcciones del tipo: el problema radica en su falta de bondad, habia en él un aura de bondad".

Por otro lado, y sin necesidad de quercr llegar a la máxima de ser es sinónimo de estar situado, la identificación, cualquier identificación, parece descansar, al menos en el fondo, en la posibilidad de localizar en cl sistema espacio-temporal unificado de las cosas particulares de las que hablamos (Strawson, 1959: 38). Esta premisa, considerada también bajo el prisma de la ostensión diferida ${ }^{5}$, no pretende identificar la existencia con la ubicación, ni identificarnos por ello con ciertos extremos de la hipótesis localista, pero sí puede permitir intuir la relación entre construcciones existenciales y posesivas y las construcciones locales, sin querer, por ello, decir que las expresiones espaciales sean más básicas, gramatical y scmánticamente, que los diversos tipos de expresioncs no espaciales, sirviendo sistemáticamente de plantilla estructural para otras expresiones, ya que la organización espacial tiene una importancia máxima en el conocimiento humano: que nos sirvamos de transposiciones espaciales para materializar otras experiencias no quiere decir que ello se haga sistemática y obligadamente, sino que hay una tendencia, siendo esa tendencia de nuestras expcriencias físicas, pero estas experiencias no son exclusivamente espaciales.

Estos comentarios son nuevamente para justificar casos como los siguientes: ante la pregunta ¿dónde está Juanma?, la respuesta no tiene por qué ser un complemento de lugar, aunque se csté preguntando por él, pues se puede responder está pegado a la pared o está con su mujer, y las respuestas seguramente satisfarán plenamente las necesidades de información del interlocutor. De esta forma, también se intenta justificar teóricamente que verbos de contacto, como adherir, adosar, agregar, etc., que aparentemente no parecen ser verbos que desarrollen una localización, son verbos con algún grado de localización necesaria. $O$ que verbos como tener o haber puedan desarrollar construcciones locales, siendo considerado el complemento de lugar obligatorio.

\section{CONSTRUCCIONES LOCALES ESTATIVAS}

La consideración de una construcción local como estativa supone su oposición a direccional, es decir, señala un lugar en dóndc o ubi. Debemos, por tanto, distinguir claramente entre a) construcciones que no tienen una incidencia espacial, aunque son localizables, es decir, que uo se construyen obligatoriamente con un complemento de lugar, aunque referencialmente pueda ser concebible algún tipo de movimiento (bailamos por toda la discoteca) o ubicación (comimos en Casa Cantó); b) construcciones con incidencia espacial obligatoria,

4 Para las peculiaridades sintácticas y semánticas que supone la consideración de una persona como hase de localización, y a veces también como figura, debe consultarse Cifuentes y Llopis (1996).

5 La ostensión diferida sc puede emplear cuando el hablante escoge como función rcforencial aquella función que liga cl demonstratum al referente que tiene el mayor grado de validez. Por ejemplo, en un bar se dice está sentado en la mesa 5 mientras se señala una detcrminada consumición. 
la cual puede venir representada en b.1.) un desplazamiento $0^{6}$, y que podrá subespccificarse según el origen, el camino dado por la dirección, y la meta (llegó a la Universidad de Alicante), o en b.2.) una ubicación, siendo estos últimos los que pretendemos acoger bajo la denominación de estativos. Así pues, un verbo local estativo será aquél que posibilite de forma obligatoria un complemento de lugar que no indique dirección o desplazamiento, lo que traducido a esquemas mentales supone enfrentar, genéricamente, el desplazamiento frente a la contención, y su consiguiente diferenciación sintáctica por cl conjunto de términos relacionantes con los que pueden construirse.

A1 analizar las estructuras dirccionales (Cifuentes, 1999) comprobamos cómo era importantísimo distinguir si la figura se verbalizaba como sujeto agente del desplazamiento o no, pues si la figura se da como agente del movimiento desarrollará la función de sujeto (siendo la construcción resultante in(ransitiva), pero si es otro elemento cl que cumple esa función, se mustrará como complemento directo, y el agente del movimiento como sujeto (y la construcción transitiva):

Cristina fue a La Vila.

Cristina llevó a la niña al colegio.

Esta importantísima distinción nos permitió explicar de otra manera las propuestas inacusativas, pues no se trata de que el sujeto de los intransitivos de desplazamiento sea paciente o tema (como plantea la hipótesis de la inacusatividad), sino que, evidentemente, es el objeto localizado (o figura), pero eso no supone otorgarle automáticamente un papel pasivo de tema o paciente, pues el desplazamiento necesita un agente (como demostramos sintáctica y semánticamente en su momento). En las estructuras transitivas no es agente la figura, pues se dará como complemento directo, reservando dicho papel semántico al elemento que actíe como sujeto, que, referencialmente, pucde acompañar a la figura o no. Pero en las estructuras intransitivas es cl sujeto quien asume un doble papel, el de agente causante de la acción (y la hay, porque hay un desplazamiento), y el de objcto localizado, porque es él el que se desplaza (sea real o imaginariamente).

En el caso de las construcciones estativas, hay una gran similitud con las estructuras de desplazamicnto, pues el objeto localizado puede darse como sujeto o como complemento directo, lo que originará estructuras transitivas e intransitivas:

\section{Juama puso el sombrero en la percha. Juanma residia en una gran mansión.}

De igual forma, en principio es posible afirmar que en las cstructuras transitivas, al ser la figura el complemento directo y tratarse de una nueva ubicación, el sujeto será el agente del cambio de posición, o el causante de la situación local que tiene la figura? ${ }^{7}$. Sin embargo, cvidentemente, en el caso de las estructuras intransitivas no va a ser posible la norma del sujeto como sujeto agente, pues al indicer la mayoría de estas construcciones un estado

6 Para un estudio de la expresión del desplazamiento en español debe consultarse Cifuentes, 1999; Crcgo Garcia, 2000; y Morimoto, 2001.

7 El caso excepcional de las estructuras impersonales no lo vemos como una negación de la regla general: habia una mosca en la sopa. 
local, el sujeto será tema (Juanma vive en San Vicente), y ésa scrá la regla general. Ahora bien, hay algunos casos que parccen sugerir otra explicación, como, por ejemplo, reinar, intervenir, mediar, arraigar, afincar, huronear, ministrar, sembrar, exponer, parar, pisar, aparecer; o muchos verbos pronominales que parecen haberse especializado tanto en esta forma que están a un paso de convertirse en intransitivos con incrementación pronominal obligatoria. Por ejemplo, empezando por el final, verbos como agolpar o apoltronar, son verbos transitivos, luego su sujeto es agente, y la figura, el objeto localizado, se da como complemento directo. Ahora bien, estos verbos ( $y$ algunos otros) parecen haberse especializado como pronominales, de forma que dificilmente podemos encontrar ejemplos en los que la figura no coincida con el propio sujeto:

?Agolpó a los niños en la puerta del cine.

?Apoltronó a la abuela en el sillón.

Lo que quiero decir con todo esto es que, verbos de este tipo, si en algún momento se restringen en su combinatoria exclusivamente al referente del propio sujeto (que viene dado en forma de pronombre, de mancra que tuviéramos una incrementación pronominal obligatoria), tendremos verbos intransitivos en los que la incrementación pronominal obligatoria será un resto sintáctico de su primitiva función sintáctica de complemento directo. En estos casos, entonces, podríamos entender que el sujeto (apoyado por la incrementación pronominal obligatoria) es agente y tema de la acción.

Los niños se agolparon en la puerta del cine.

La abuela se apoltronó en el sillón.

En cuanto a los primeros casos, lo cierto es que se trata de verbos que suponen un agente como sujeto en su construcción, ya que hay actividad, como lo demuestran, por otro lado, la aplicación de las pruebas para demostrar que un sujeto es agente ${ }^{8}$ :

Reinó en España durante 25 años.

Intervino en el asunto.

Medió entre los dos contendientes.

Arraigó en Alicante después de recorrer media Europa.

Se afincó en Alicante.

Huroneaba en nuestros asuntos.

Ministra en la Audiencia Provincial.

Sembró en terrenos del Ayuntamiento.

Expone en la Sala Tifos.

La manifestación puró delante de la sede del PP.

Pisó sobre la arena.

Aparecieron infinidud de indios en lo alio de la colina.

La explicación para ello seguramente tiene que ver con el origen y la formación de los verbos, pues cn el caso de intervenir y arraigar parece haber una idea de desplazamiento

8 Todos estos verbos admiten la forma imperativa, la subordinación a verbos del tipo ordenar o prometer, la modificación mediante adverbios de vohuntad, y la aparición de subordinadas finales, construcciones todas ellas que reclaman la presencia en la frase de un argumento agente (Vera Luján, 1994). 
en el origen, to que puede haber originado el conato de actividad y, por ello, de agentividad: en el caso de intervenir es evidente, por su vinculación transparente con venir, pero en el caso de arraigar puede resultar más confuso, pues viene del latín radicare, construido, a su vez, sobre radix, -cis, y mi hipótesis es que en el origen tuvo que haber algún tipo de amalgama de desplazamiento, pero con el tiempo parcec haberse ido perdiendo conciencia de ella, habiéndose convertido en posicional, quizás, como en tantos otros casos, por relación motonímica con el resultado.

El caso de afincarse es bien sencillo, pues como he intuido con los primeros casos, el pronombre es resto de función, por lo que originariamente estaría vinculado con un complemento directo, y, por ello, el sujeto es agentivo.

Huronear sc ha construido sobre hurón, por lo que, como comentaremos más adclante, es posible imaginar una amalgama causativa en su formación, algo parecido a *hacer como el hurón $n^{y}$, lo que explicaría la agentividad del sujeto.

El caso de reinar es parecido, pues es un verbo denominativo latino formado sobre regnum, derivado de rex, -gis, y debiéramos imaginar alguna amalgama en su formación como * tener o poseer el reino.

Mediar tendría también alguna explicación similar, pues, siendo también formación latina, se construyó el verbo medio, sobre medius, - $a$, -um, que tenía los dos usos, transitivo e intransitivo, pero al pasar al español necesitỏ reforzar el relacionante sobre el que estaba construido (medio) e hizo que fuera necesario un elemento telacionante como entre, en, etc., pero tiene un origen transitivo en el significado, con lo cual la agentividad es obvia ${ }^{10}$.

Muy parecido a huronear o reinar es ministrar, tratándose de un verbo latino (ministro) formado sobre un sustantivo (minister; -tri), pudiendo imaginar una amalgama causativa en su formación, parecida a *hacer de minister.

El ejemplo con sembrar (o sementar) es interesante: este verbo puede dar lugar a construcciones tanto transitivas como intransitivas: sembró trigo en la arena vs. sembró en la arena, lo cual podría suponer una explicación en términos de complemento directo interno, pero implicaría hacer intervenir explicaciones distintas para ejemplos como sembró el campo, sembró décon trigo el campo. La explicación a este comportamiento tan diverso, y que, creo, acoge también la idea de complemento directo interno, viene dada, de nuevo, por la formación del verbo: semino cstá formado a partir de semen, -inis, tratándose de un verbo transitivo en el que es posible imaginar una amalgama local de la figura (semen, -inis), algo parecido a *localizar una semilla en, y, al tratarse semen de algo muy genérico, puede necesitar de especificaciones de éste (trigo, avena, etc.). En cualquier caso, las variantes

9 Siempre que expongamos una paráfrasis explicativa de una posible incorporación conceptual se verá acompañada de un asterisco, indicando con ello no que se trata de una construcción anómala, sino que es una forma de acceder a la posible estructura conceptial del verbo considerado de forma sintética, pero que evidentemente no es su estructura conceptual, pues vicne expuesta en una lengua, sino que es una manera de aproximarnos a su estructura conceptual mediante las funciones abstractas fundamentales que dicha paráfrasis supone.

10 Según Niemeyer, el término medius no es empleado en latín clásico para formar un verbo, sino que es en periodo medieval - a partir del siglo VII - cuando empieza a emplearse mediare y sus derivados (mediator; mediatio, mediatoria, mediatrix, mediatura). El verbo cra transitivo en el sentido de «cortar por la mitad», e intransitivo en «estar en medio»; pero con el significado que estamos considerando, «negociar, mediar, efectuar por mediación», era transitivo:

Mediantibus Inter. Eos domesticis et amicis illorum placilum.

Confirmata Inter Los pace imperatrice haec omnia mediante. 
transitiva o intransitiva combinadas con una base de la localización (sembró el campo, sembró en el campo) suponen una figura implicada, y que cl sujeto no sea la figura, sino el agente de la acción.

El caso de exponer si que puede ser denominado de complemento dirccto interno, pues la variante intransitiva está especializada en el significado «mostrar un artista [sus obras]», por lo que tampoco es el sujeto la figura de la localización.

El caso de parar es también interesantísimo, aunque su origen latino no deja transparentar amalgama alguna, y sicndo su evolución semántica un deleite intelectual. En cualquier caso, lo que interesa señalar es que el verbo puede ser tanto transitivo como intransitivo, pudiendo ser el sujeto un ente animado en cualquiera de los dos casos, es decir, que en la variante intransitiva, como ocurría con los direccionales, confluirán en el sujeto las funciones de agente y figura.

El verbo pisar también tiene la posibilidad de construirse como transitivo o intransitivo con el mismo tipo de sujeto", pero éste es un caso más complicado, pues tengamos en cuenta que también puede funcionar como construcción partitiva: le pisó la cara / le pisó en la cara. Esto último podría querer decir que, a pesar de que no se transparenta en cl origen ${ }^{12}$, es posible entender una figura implicada ( ${ }^{*}$ pisotón, pisada), por lo que el sujeto desempeñaría una función agentiva.

El verbo aparecer no es agentivo. Ahora bien, cuando el sujeto es animado, la idea de «mostrarse, ser visible», que estaba presente ya en lalín, puede hacer suponer una cierta idca de acción o movimiento, pues un ente animado no aparece por casualidad, sino por causalidad, concretamente interna, al tratarse de él mismo. Es así que el significado «estar, hallarse» que estamos utilizando para esta construcción parece darse exclusivamente con entes no animados, pues de lo contrario podría entenderse algún tipo de dinamicidad, y, por ello, agentividad, como se puedc comprobar si aplicamos las reglas de agentividad, especialmente efectivas si se trata de fantasmas o seres ocultos.

\subsection{Desplazamiento interior y cambio de posición}

En Cifuentes (1999) expusimos la diferenciación entre verbos locales estativos transitivos y verbos direccionales interiores transitivos, que, en muchos casos, puede prestarse a confusión ${ }^{13}$. La diferencia fundamental que pucde venir configurada en la pareja de verbos meter-poner, cs debida al rasgo de dirección. Una localización con poner no implica ninguna trayectoria o dirección, únicamente una localización en dos fases: el objeto está localizado en algún lugar y luego en otro; lo que es expresado es siempre la localización final, pero no hay un desplazamiento, aunque sí puede haber algún tipo de movimiento, y máxime si se trata de un cambio de ubicación. Boons et al. (1976) y Lamiroy (1991: 73) han propuesto otro criterio para distinguir entre complemento direccional y posicional: un complemento direccional excluye que la persona esté prescnte en el lugar indicado por el

11 Aunque haya significados especializados como transitivos o intransitivos, según los casos, este hecho no importa para la posibilidad general de construirse con un mismu sujeto como transitivo o intransitivo.

12 Ernout y Meillet (1959) únicamente hablan de una raíz * peis que se aplica a la técnica de la pistura, con ayuda de una especie de pilón o mortero.

13 Yen otros muchos a jdentificación. 
complemento locativo antes de que se realice el desplazamiento; condición ésta que está ausente en el caso de un complemento posicional.

En los direccionales interiores hay un desplazamiento dado en la dimensión interior (dentro/fuera), luego los relacionantes con los que pueden aparecer marcarán siempre este tipo de conceptualización, y las bases deben poseer la dimensión interior, es decir, no pueden ser superficies, por ejemplo. Además, como cn todo desplazamiento, resultará posible conceptualizar la partida, la llegada, o el camino. Por contra, los posicionales indican una localización en dónde (ubi) en cualquicra de las cuatro dimensiones espaciales (vertical, lateral, perspectiva e interior), de ahí que la combinatoria relacionante sea distinta. Por otro lado, no se conceptualiza un desplazamiento sino una situación: en todo cambio de posición hay un movimiento, pero no un desplazamiento direccional, prueba de ello es la no combinatoria con relacionantes direccionales, reflejo de que al ser el cambio de posición un movimiento físico muy corto y breve, pues pragmáticamente debe serlo, no tiene relevancia el movimiento (lo que lleva implícito una ausencia de desplazamiento), sino la nueva situación, resultado de un cambio de cstado físico local, pero no se dinamiza el desplazamiento.

*Lo metió en la silla vs. lo puso en la silla.

Lo metió en la mesa vs. lo puso en la mesa ${ }^{14}$.

Le metió el dedo en el ojo vs. le puso el dedo en el ojo.

Lo metió hasta el fondo us. "lo puso hasta el fondo.

Lo metio hacia dentro vs. ?lo puso hacia dentro ${ }^{15}$.

La metió desde muy lejos ${ }^{16}$ vs. *la puso desde muy lejos.

Además, debcmos considerar que muchos verbos interiores pueden combinarse con $a$ con un sentido adlativo, aspecto que contrasta con los verbos posicionales:

Metió la mesa al cuario vs. *puso la mesa al cuarto.

Entró a la casa vs. * Esiá a la casa.

Un aspecto pragmático muy curioso, y que puede aunar lo que llevamos dicho y la caracterización señalada por Boons et al. y Lamiroy de que el complemento posicional exige que figura y causa de la localización estén en el mismo lugar, mientras que el complemento direccional excluye que la persona esté presente en el lugar indicado por el complemento locativo antes de que se realice el desplazamiento (aunque esta última parte no tiene por qué ser así: mételo en la caja vs. ponlo en la caja, donde la localización de la persona es la misma cn los dos casos), es el hecho de que el cambio de posición supone un movimicnto, pero tiene que ser corto y breve, según hemos dicho, para que no se conceptualice como

\footnotetext{
14 En admite dos significaciones (Cifuentes, 1996: 143 y ss.), según juguemos con la dimcnsión interior o con la dimensión vertical: interioridad o «en el interior de los límites de una superficie», entendiéndose las superficies como contenedores. $\Lambda$ este respecto observamos cómo en el ejemplo propuesto meter selecciona obligatoriamente la dimensión interior (*lo metió encima de la mesa), y poner, aun pudiendo teóricamente seleccionar las dos, sc decanta por la vertical: ?lo puso dentro de la mesa us. lo puso encima de la mesa.

15 Este ejemplo puede resultar válido, pero no para responder a una localización, sino a una predicación modal: ¿dónde lo puso?, *hacia dentro vs. ¿cómo lo puso?, hacia dentro.

16 Fstamos ubicando la figura, no el agente.
} 
desplazamiento (con lo cual explicamos también la doble posibilidad que tienen algunas escenas de conceptualizarse como movimiento posicional o como desplazamiento interior, dependiendo del sujeto de la cnunciación), y ello supone excluir bases grandes, pues supondrían la conceptualización de un desplazamiento e implicarían que la persona o causante no estuviese en el lugar de dicha base.

Io metió en/dentro de la casa.

?Lo puso en/dentro de la casa.

Lo llevó aldentro de la casa.

La direccionalidad de meter está patente desde el momento en que podemos sclcccionar cualquiera de las fases del desplazamiento, cosa imposible con poner. Es particularmente interesante en cste caso la selección del camino o medio, pues, al tratarse de la dimensión interior, dicho camino debe entenderse como el límite o la frontcra de paso entre el interior y el exterior, cosa totalmente imposible con poner, donde las mismas estructuras lo único que pucden significar, si acaso, es extensión indeterminada en un lugar ubi.

Lo metió dentro de la caja (quo) vs. lo puso dentro de la caja.

Lo metio en la casa (quo) vs. lo puso en la estanteria (ubi).

Lo metió descle arriba (unde) vs. ?lo puso desde muy lejos.

Lo metió hasta el fondo (unde) vs. *lo puso hasta dentro.

Se metió por la ventana (qua) vs. ?lo puso por la ventana.

Se metió por el agujero (qua) vs. "lo puso por el agujero.

De igual forma, los verbos del tipo de meter, al ser direccionales, implican un determinado sentido y orientación. Así, meter supone la dirección interior, con un sentido adlativo, y aunque se puede orientar libremente, como lo demuestran los ejemplos anteriores, su sentido siempre es adlativo en la dirección interior. Los verbos del tipo de poner no implican los aspectos anteriores, lo cual nos explica combinatorias como las siguientes:

Lo metió en la mesa.

* Lo metió ficera de la caja ${ }^{17}$

Lo puso en la mesa.

Lo puso fiera de la caja.

Por otro lado, el comportamiento con bases personales, según pusimos de manifiesto anteriormente (Cifucntes \& Llopis, 1996: 124-126) es bastante distinto. En primer lugar, cl sentido común, revestido en forma de pragmática, nos dice que un movimiento interior hacia una base personal va a ser muy limitado, pues, si es físico, la base corre serios peligros de dejar de existir, de ahí que muchos usos sean conceptualizaciones mctafóricas (le metió unas ideas muy extrañas). Parece más claro todavía cuando la figura es animada: se metió dentro de él para analizarlo. Sin embargo, el posicionamiento con una base personal es muy distinto y no tiene límites, pues podemos posicionar una figura respecto de una base en cualquier dimensión, como ya dijimos antes, cosa que no es posible con los interiores:

17 Podria ser un ejemplo válido si consideramos fuera no como término de la dirección, que es como lo estamos considerando, sino como localización genérica. 
* Lo metió encima del armario.

?Lo metió delante de Juan.

Lo puso delante de Juan.

Aunque hayamos ejemplificado el funcionamiento de posicionales y direccionales interiores con poner y meter, siendo ambos elementos que seleccionan la localización final en su orientación no marcada, las mismas pruebas que hemos expuesto para su diferenciación pueden aplicarse a aquellos elementos que están oricntados desde el origen (quitar vs. sacar), con la pequeña diferencia de que, en este caso, los direccionales intcriores tienen menos problemas para seleccionar bases personales.

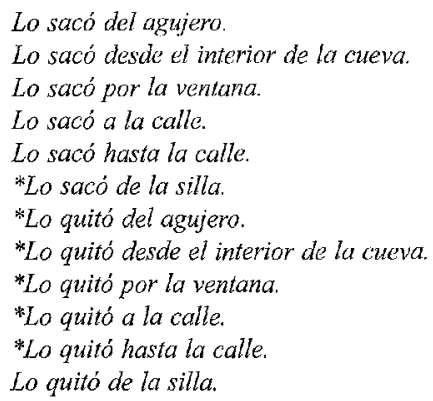

Una última característica que podemos utilizar como mecanismo diferenciador de estructuras direccionales interiores y posicionales, es la referida al aspecto de los mismas. Las construcciones con meter, es decir, direccionales interiores en su conjunto, por necesitar un punto de culminación, una situación final para poder realizar la acción verbal, se entienden como eventualidades télicas, Las cstructuras posicionales que pueden venir representadas por un verbo como poner, no implican un cambio de localización por desplazamiento, como en el caso anterior, pero sí un cambio de lugar de referencia, describiendo una situación dada en un momento determinado, breve y sin pasos intermedios, frente a las construcciones anteriores, que son acontecimientos télicos complejos, con pasos intermcdios y que necesitan un tiempo de desarrollo. Lals correlaciones temporales que manifiestan así lo parecen demostrar.

Meti el coche en el garaje en tres minutos.

* Meti el coche en el garaje durante tres minutos ${ }^{18}$.

¿Cuánto tiempo has empleado para meter el coche en el garaje?

* Durante cuánto tiempo metiste el coche en el garaje?

* ¿Desde cudindo metes el coche en el garaje?

¿A qué hora metiste el coche en el garaje?

Lo meti un poco.

18 Construcciones como ésta, o alguna otra señalada como agramatical más abajo, podrían parecer aceptables y válidas en algunos contextos. Sin embargo, fijémonos que en modo alguno conciemen a la temporalidad de la acción del desplazamiento de meter, sino al resultado de la misma: dejé el coche en el garaje. 
* Puse el libro en la mesa en tres minutos.

* Puse el libro en la mesa durante tres minutos.

* ¿Cuánto tiempo has empleado para poner el libro en la mesa?

* ¿Durante cuinto tiernpo pusiste el libro en la mesa?

* ¿Desde cuándo pones el libro en la mesa?

* ¿A qué hora pusiste el libro en la mesa?

* Io puse un poco.

Por otro lado, el desarrollo de la acción que suponen las construcciones direccionales, frente a las posicionales, también puede ser objetivado con otras pruebas:

Esía metiendo el libro en el cajón, pero le cuesta hacerlo.

* Está poniendo el libro en el cajón. pero le cuesta hacerlo.

Ha terminado ya de meter el coche en el garaje.

?Ha terminado ya de poner el libro en la mesa.

No nos debe extrañar el posible carácter resultativo de las acciones anteriores, aun a fuerza de parecer algo forzadas las construcciones, porque debemos recordar, con Demonte (1991: 125-126), que las realizaciones y los logros, estructuras télicas, podían descomponerse en los siguientes rasgos:

realizaciones: [ + actividad, +resultado]

logros: [-actividad, +resultado]

La producción de un resultado visible parece por tanto característica común a la telicidad, y por ello que, aunque forzado, resulte posible entendcr algunas constricciones direccionales interiores y posicionales de forma que se privilegie ese contenido resultativo.

Por otro lado, también debemos señalar que direccionales interiorcs y posicionales difieren también en un aspecto muy significativo: los direccionales interiores (en sus usos transitivos, que son los que venimos considerando en su posible convergencia con los posicionales, también transitivos) pueden desarrollar un complemento que suponga una medida, pues al conceptualizar un desplazamiento éste se puede medir y cuantificar. Por contra, los posicionales, como no implican ningún tipo de desplazamiento, no pucden combinarse con este tipo de estructuras:

Lo metió dos metros.

Lo introdujo tres centimetros.

*Lo puso tres metros.

Lo colocó dos centímelros ${ }^{19}$.

Así pues, quede entonces bien establecida la diferencia entre posicionales (verbos locales estativos transitivos) y direccionales interiores.

19 Obsćrvese que un ejemplo como to paiso dos metros bajo tierra sería diferentc a los anteriores, pues no supone una cuantificación o medida de la direcionalidad, sino una manera de señalar una posición determinada:

Lo metió dos metros (¿cuánto lo metió?)

Lo puso dos metros bajo lierra (* ¿cuánto lo puso? vs. ¿dónde lo puso?). 


\section{VERBOS DE MANFRA DE POSICIÓN}

Los verbos de manera de desplazamiento han sido muy estudiados en español, constituyéndose, sin duda, en uno de los temas fundamentales de la gramática del desplazamiento en español (Cifuentes, 1999; Crego, 2000; Morimoto, 2001), y queriendo identificar con ello a aquellas construcciones en las que sc indica la manera en que se desarrolla el proceso. Sin embargo, lo que podría ser el paralelo de estas construcciones con verbos estativos ha sido muy poco tratado.

Talmy $(1975,1985,2000)$ establece la posibilidad de que el rasgo manera se encuentre amalgamado en cl verbo, expresando éste tanto la ubicación como la manera de estar de la figura, llegando incluso a hablar de verbos de postura ${ }^{20}$. Sin embargo, en su conceptualización del tema, distingue los rasgos manera y causa como elementos diferentes que se pueden amalgamar, o fusionar, con el verbo, y lo hace de una manera que nosotros no seguiremos exactamente, especialmente cn lo referente a causa.

Jackendoff (1990: 91) también reconoce que puede aislarse un grupo de verbos situativos de modo de acción (como sentarse, por ejemplo), que describen la configuración espacial interna de sus figuras, paralelos a los verbos de manera de movimiento.

Lamiroy (1991: 65-74) distingue junto a los verbos de desplazamiento y los verbos de manera de desplazamiento, un tercer grupo dc verbos de movimiento que indican, más que un desplazamiento del sujeto de un lugar a otro, un cambio de postura del cuerpo: tumbarse, sentarse. Como yá expusimos anteriormente, los verbos de movimiento corporal, en principio, no tienen por qué implicar desplazamicnto, luego aun siendo verbos que pueden necesitar obligadamente una estructura local, no tiene por qué ser direccional, sino más bien situativa.

Ashcr y Sablayrolles (1995) también distinguen en su clasificación de verbos de movimiento, un grupo de verbos de cambio de postura, en los cuales se realiza una relación física especial entre una o más partes de la entidad que se mueve y la localización introducida por el sintagma prcposicional: arrodillarse, por ejemplo.

En los últimos años, han aparecido diversos artículos donde se trata, de alguna manera, la cucstión de los verbos de manera de posición, destacando especialmente la edición de Newman (2002), aunque Ncwman utiliza las denominaciones verbo de postura y verbo de posición, prefiriendo, sin duda, la primera, que acoge mejor los verbos más estudiados, sit, stand y lie, denominados verbos de postura cardina ${ }^{21}$.

Estas consideraciones de verbos de cambio de postura, constituyen precedentes de lo que vamos a organizar como construcciones de manera de posición, con lo que queremos significar que no sólo se indica una posición o localización, sino también una postura o una manera de estar de la figura. Así pues, tenemos diferenciados, de momento, dos tipos de verbos locales estativos: a) situativos, que indican lugar en dónde, y que pueden ser transitivos

20 Los verbos de postura definen posturas n orienteciones que son asumidas por el cuerpo humano o por objetos tratados de forma comparable al cuerpo (Talmy, 2000: 79).

21 En lingúística cognitiva, los estudios sobre los verbos de poslura han desarrollado dos aspectos fundamentalmente: a) los que se centran en la polisemia de los mismos (van Oosten, 1982; Gibbs, Beitel, Harrington y Sanders, 1994; Serra Borneto, 1996, Kuteva, 1999; Newman (2001), y b) los que se centran en los procesos de gramaticalización que conllevan los verbos de postura (Austin, 1998; Kuteva, 1999; Newman, 2002; Newman y Rice, 2001, 2004) 
o intransitivos, siendo los transitivos agentivos, y la mayoría de los intransitivos de estado; b) verbos de manera de posición. El problema fundamental de estos verbos de manera de ubicación va a residir en su significante, es decir, y por utilizar planteamientos cognitivistas, toda construcción lingüistica es simbólica, y por ello producto de una asociación entre significante y significado. El significado es cl de localización + manera de estar localizada la figura, pero su significante, es decir, los rasgos formales que permiten identificar la construcción al estar asociados con dicho significado, son más complicados.

Quizás la más clara diferenciación entre los dos grupos de verbos sea que los verbos de manera de posición pueden ser parafraseados por una construcción predicativa en forma de participio más un verbo estativo $0^{22}$, indicando el modo de la posición. Esta construcción, en la mayoría de las ocasiones tambićn es sintácticamente posible con algunos verbos estativos que son producto de otra amalgama o incorporación, pero cn modo alguno indican una posición

Atravesó un madero en la calle / puso-dejó atravesado un madero en la calle.

Acomodo a los visitantes en el despacho / dejó-puso acomodados a los visitantes en el despacho.

Se arrodilló en la iglesia / se quedó-puso arrodillado en la iglesia.

Puso una joya en el estuche / dejó-"puso puesta una joya en el estuche.

Fijó su residencia en Alicante / dejó- ${ }^{*}$ puso fijada su residencia en Alicante.

Guardó los documentos en la caja fuerte / dejo-*puso guardados los documentos en la caja fuerte.

Si nos fijamos en los tres primeros ejemplos, comprobamos cómo las paráfrasis indican una manera de estar de la figura (atravesada, arrodillada o acomodada). Sin embargo, en los tres últimos ejemplos, que no son verbos de manera de posición, no es aceptable su consideración semántica como manera de estar de la figura: puesta, fijada, guardada, de ahí, entre otras cosas, que no sea posible su combinación con paner. Quiero aclarar mejor que con manera de estar de la figura es necesario entender una postura, una posición, y si algo está puesto, fijo o guardado no tiene ninguna posición o postura característica que la determine. No obstante, es preciso scñalar que si bien esta es una diferenciación clara entre verbos de manera de posición y verbos estativos, hay un grupo de verbos estativos, los que son producto de incorporaciones locales (figura, base o relacionante) que también permiten la paráftasis verbos estativo + participio, pero no indican una posición o postura sino subsidiariamente.

22 De forma similar a los verbos de manera de desplazamiento, que pueden utilizarse en forma de gerundio, combinados con un verbo de desplazamiento, para indicar el modo o la manera del desplazamiento, siendo este uso imposibic con los verbos de desplazamiento:

Juan fue al parque corriendo.

* Iuan fue al parque entrando.

Berthcle (2003) generaliza la idea de que todas las lenguas usan el csquema Auxiliar + participio para expresar la manera de posición, afirmación ésta que no sé si es demasiado categórica, aunque sí tiene muy de cierto que son muchas las lenguas que usan este esquema formal. 


\title{
3.1. Verbos de manera de posición: contacto
}

Hay un grupo significativo de verbos que, en alguno de sus significados (y muchos de ellos en los más representativos), posibilitan construcciones locales con la idea común de "contacto" ${ }^{23}$ : adherir, adosar, adscribir; adunar ajustar, anexionar, atar, conectar, empalmar, juntar, pegar, soldar, sujetar, uncir, unir, etc. Estos verbos, con un claro valor resultativo, tienen una característica definitoria clave, y es que el complemento de lugar viene introducido por la preposición a. No digo con ello que no pueda aparecer otra preposición, lo que digo es que la preposición por excelencia es $a$, con lo que encontramos complementos locales introducidos por $a$. Ya Roegiest (1980: 80 y ss.) nos hablaba de valores de $a$, conmutables con $e n$, que serían equivalentes en el significado a junto $a$ :

\author{
La hiedra se adhiere al tronco. \\ Lo adosó a la pared. \\ Ajustó el cajón a la mesa. \\ Lo ató al coche. \\ Sujetó el caballo al carro.
}

En todos estos casos se indica que la figura, que es complemento directo ${ }^{24}$, ya que las estructuras son todas transitivas, se encuentra en una determinada posición, y es en contacto con la base. Más aún, se indica un estado resultativo de ese contacto. Este hecho nos explica también cómo hay muchos verbos que no desarrollan valores locales, como abrochar; ceñir; abrazarse, cogerse, etc., pero quc, en determinadas construcciones semejantes a las anteriores, desarrollan valores de manera de posición indicando contacto, mejor dicho, estado resultativo de ese contacto:

\section{Se abrochó la camisa a la nuez. \\ Se ceñia el pañuelo a la cabeza. \\ Se abrazó a la madera. \\ Se cogieron a los palos que colgaban.}

Fs claro que en todas estas construcciones los valores locales se encuentran un tanto mitigados, a expensas de los valores «modales» dados por la manera de estar posicionada la figura, como tambićn ocurría con los verbos de manera de movimicnto.

\subsection{Verbos de manera de posición: sensación}

Hay un grupito de verbos, como acomodar, apalancar, apoltronar, arrellanar, etc., que indican una manera de posición, pero no se trata de una posición física concreta, como

\footnotetext{
23 En cl planteamiento de Talmy, algunos de estos verbos quizás debicran entenderse mejor como resultado de la fusión o amalgama del componente verbal con el rasgo opcional causa, y no con el de marera.

24 Si el sujeto, causa externa de la localización, y el complemento directo coinciden referencialmente, tendremos, evidentemente, una cstructura pronominal (independientemente de los casos de intensificación con se).
} 
puede ser sentado o pegado, sino de los resultados, normalmente de comodidad o placidez, que la figura experimenta en esa postura ${ }^{25}$ :

Acomodó a los visitantes en el despacho.

Se apalancó en el sillón.

Se apoltronó en la butaca.

Se arrellanó en su sillón.

En todos estos casos no existe una postura física predefinida de acomodamiento, apalancamiento, apoltronamiento o arrellanamiento, ahora bien, frente a ejemplos como guardar, conservar o grabar, sí podemos decir de alguien, o algo, que está cómodo, apalancado, etc., indicando la postura que tiene, cosa que no podemos hacer con gwardar u otros, pero es una postura que podemos deducir por el contexto y la sensación que parece que produce esa postura en la figura.

Convienc scñalar, por otro lado, que aunque en alguno de estos verbos pudiera rastrearse en el origen una determinada postura física, dada por el clemento del que deriva el verbo, esta idea está totalmente perdida, como lo demuestra el significado actual. Así, en apalancar, arrellanar, o apoltronar, la idea básica de su significado es «acomodarse, qucdarse en un sitio con toda comodidad», no hay transparencia del latín palanga («rodillo, garrote»), ni de pullitru, o, mejor, poltrona («silla poltrona»), ni de planus («plano, llano»).

Así pues, de algo podemos decir que, como resultado de una postura, se encuentra acomodado, apalancado, apoltronado, arrellanado, pero en modo alguno guardado, conservado o grabado. Si guardamos, conservamos o grabamos algo en algún sitio u objeto, no lo ponemos cn una postura, sino que lo ponemos en una posición distinta de la que tenía antes, hay un cambio de ubicación o de estado, pero con apalancar, arrellanar, apoltronar o acomodar no nos centramos en un cambio de estado o ubicación, sino en el resultado, placentero y de comodidad, en este caso, que produce una determinada postura o posición de la figura situada en un determinado sitio u objeto.

\subsection{Verbos de manera de posición física}

Debemos aclarar, porque puede prestarse a confusión, que las denominaciones que estamos usando son metodológicas, en tanto que son abjeto de una precisión terminológica. Quiero decir con ello que porque denomine a un grupo de verbos como de manera de posición física, sólo es su denominación, pues es claro que los otros dos grupos de verbos de manera de posición también representan una posición física, pero los primeros los hemos caracterizado metodológicamente por la idea de contacto, y los segundos por la idea, terminológica también, de sensación, queriendo acoger con ello la noción de comodidad que parecía presidir paradigmáticamente los mismos.

Este nuevo grupo de verbos, que acogen construcciones con acostar, afrontar, apartar, arrodillar, atravesar, colgar, echar, encarar, inclinar, postrar, postremar, rectinar, recostar, respaldar, sentar, tender, tirar, tumbar, ctc., siempre señalan una posición física espacial de la figura:

25 No nos debe extrañar demasiado esta visión «perceptiva» de la postura, pues la mayoría de los estudios están de acuerdo en las bases antropocéntricas de los verbos de postura (Lemmens, 2002: 104). 


\section{Acuesta al niño en la cama. \\ Pepe se arrodilló en la iglesia. \\ Échate en la cama. \\ Se inclinó ante el general. \\ Lo sentó en el suelo.}

En los ejemplos anteriores, siempre se expresa una postura física espacial de la figura: * pon al niño acostado, *se puso de rodillas en la iglesia, * se puso echado en la cama, *se puso inclinado ante el general, *lo puso sentado en el suelo. En todos estos ejemplos, o similares, la caracteristica definitoria es la postura física espacial de la figura, es por ello que, al igual que ocurre con el resto de verbos de mancra de posición, y a semejanza de los verbos de manera de movimiento, pueden predicarse sin el componente incidencia cspacial, y por ello predicar exclusivamente su contenido modal:

Se acostó muy tarde.

No podia arrodillarse.

No sabia echarse sin armar ruido.

Al inclinarse se le veian los calzoncillos.

Sólo se sentaba cuando estaba callada.

En cualquiera de los casos anteriores, y a diferencia del conjunto de los verbos estativos, exclusivamente locales, los verbos de manera de posición pueden darse cn construcciones ( $\sin$ cambiar de significado) en las que no sea necesario un complemento de lugar, porque simplemente se predica su componente modal. Ahora bien, cuando la construcción explicita un complemento de lugar éste tiene algún tipo de obligatoriedad, ya que se conceptualiza la escena local de la postura.

\subsubsection{Desplazamiento y posición fisica}

Hay un par de verbos muy interesantes dentro de este subconjunto: echar y tirar pueden funcionar como verbos de desplazamiento y como verbos de manera de posición ${ }^{26}$ :
Tírate al suelo.
Tirate en el suelo.
Lo tiró encima del sofá.
Lo tiró delante del espejo.
Lo tiró hasta la grada más alta.
Lo tiró desde atrás.
Tiró la pluma dentro del cajón.
Lo tiró por la ventana.

La explicación a un funcionamiento como el de los ejemplos anteriores no creo que resida en que se trata de casos límite entre posicionales y direccionales interiores. De nuevo, si reconstruimos pragmáticamente el tipo de escena cognitiva que verbalizan estas

26 Esta doble posibilidad no nos debe extrañar demasiado, pues algunas lenguas lexicalizan cn una sola forma verbos de postura con modo estático y verbos de postura con modo direccional (de movimiento hacia la postura (Kracht, 2003: 8). 
expresiones, nos daremos cuenta de un hecho muy interesante, y es que el desplazamiento tiene que ser corto, con toda la subjetividad métrica que aporta este adjelivo, pero con la precisión semántica que lo caracteriza. Al ser el desplazamiento corto, no nos debe extrañar que guarde estrechas relaciones con el cambio de posición, y que por ello cstos verbos constituyan un caso límite entre posicionales y direccionales en tanto que aceptan sin problemas tanto relacionantes ubi como términos quo. Además, estos verbos, parecen tener algún tipo de rasgo resultativo en tanto que indican el modo o el rcsultado posicional en que queda la figura: no vertical, sino tumbada o echada, lo cual es también un rasgo que los acerca a los verbos posicionales (especialmente a tumbar, tender, acostar y recostar. Por tanto, estos verbos, dependiendo de la escena cognitiva que expresen, pueden manifestar tanto un desplazamiento (no un desplazamiento interior) como un cambio de posición resultativo: el hablante tiene a su disposición con un mismo verbo poder describir una misma realidad conceptualizándola como desplazamiento o como cambio de posición (lo tiró al suelo, lo tiró en el suelo), aunque es claro que, algunas bases (y algunas figuras), pragmáticamente, pueden condicionar que sólo sea posible un tipo de conceptualización, porque el desplazamiento sea difícil de entender como corto, por ejemplo:
Lo tiró al abismo.
*Lo tiró en el abismo.
Tira el papel a la calle.
?Tira el papel en la calle ${ }^{27}$.

Para que estos verbos puedan ser entendidos como de manera de posición, y no como verbos de desplazamiento o como una localización genérica de la acción, es necesario, además de que se trate de un cambio de posición que no pucda ser entendido como desplazamiento, es decir, que la posible distancia sea corta o, mejor, inexistente, que la figura pueda conceptualizarse como teniendo una postura en relación a la base: tirada o echada.

La postura que expresan los verbos de manera de posición fisica viene dada por el origen románico del verbo, al ser derivado de un término que expresa una posición (cosia -en tanto costado— > acostar, recostar; aparte > apartar; través > atravesar; cara > carear; espalda $>$ respaldar; rodilla $>$ arrodillar), o por la propia evolución del término latino del que derivan (jactare $>$ echar; tendere $>$ tender; tumb $>$ tumbar).

\section{VERBOS CON INCORPORACIÓN IOCAL}

Según Talmy (1985), el esquema de acontecimiento básico del desplazamiento consta de figura, base, trayectoria y movimiento (o localización). Junto a estos componentes internos, el acontecimiento puede tener una manera o una causa. La figura es el objeto que se mueve,

27 Son curiosos estos últimos ejemplos, pues tira el papel a la calle supone concebir un desplazamiento de forma que si alguien realiza esa acción no puede hacerlo desde la calle, sino que tiene que encontrarse situado en otro lugar, una casa por ejemplo; pero esta misma escena sería imposible de expresar mediante lira el papel en la calle, pues sólo puede ser válida como localización de la acción, pero no como lugar término del desplazamiento, es decir; el sujeto que realice dicha acción no puede hacerlo desće una casa, como en el anterior ejemplo, sino que tiene que hacer el movimiento en la calle, fuera de eualquier casa. 
o que se localiza, con respecto a otro objcto (la base). La trayectoria o dirección es el curso seguido o el lugar ocupado por el objeto figura con respecto al objeto base. El movimiento, o localización, se refiere a la presencia per se en el acontecimiento de movimiento o localización. La manera se refiere a una acción o estado subsidiario al manifestado con la acción o estado principal. La mayoría de los verbos de movimiento de las lenguas indoeuropeas incorporan regularmente la manera al movimiento. Los constituyentes que especifican la figura y la base son nominales, los que especifican el camino o la trayectoria son preposicionales, y los que designan el movimiento, o localización, verbales. Evidentemente este esquema puede dar cuenta tanto del desplazamiento como de la ubicación, pues la ausencia de movimiento supone el estatismo de la ubicación, y la trayectoria es el marcador preposicional que establece la relación local entre figura y base.

La incorporación amalgamado al verbo del rasgo manera o modo de acción es una de las posibilidades que tiene de venir representado sintácticamente dicho elemento conceptual, que también puede venir representado lingüísticamente en forma de satélite, o en un elemento léxico separado, por ejemplo en forma de gerundio en las construcciones de desplazamiento. Creo haber demostrado que esta amalgama tambićn es posible en las estructuras estativas, dando lugar a lo que homos denominado verbos de manera de posición, por lo que el componente manera, que sigue siendo opcional, puede venir amalgamado al verbo, o dado de forma independiente, como en las paráfrasis predicativas que expusimos en su momento, y a semejanza de las construcciones de desplazamiento.

\subsection{Incorporación}

El concepto de amalgama de Talmy creo que puede tener una enorme semejanza con el fenómeno de la incorporación, descrito entre otros por Mardirussian (1975), Dik (1980), Mithun (1984, 2000), Lazard (1984), Baker (1988; 1996), Wotjak (1990), Sadock (1980; 1991), Morcno Cabrera (1991), Di Sciullo y Williams (1987), Roscn (1989), van Geenhoven (1998), Gerdts (1998) o Farkas y de Swart (2003).

La incorporación es un mecanismo mediante el que un sustantivo, que cumple una determinada función respecto de un verbo, se convierte en un modificador de cse verbo, obtcniéndose un nuevo verbo complejo con un argumento menos que el verbo original, es decir, se trata de la integración de sustantivos en el cuerpo sígnico, en el formativo de verbos, por lo que podriamos entenderlo como un procedimiento de formación de palabras, como ha establecido Baker (1988: 78). La incorporación, por tanto, se usa para describir construcciones en las que un verbo y uno de sus argumentos forman una unidad. No obstante, las amalgamas o incorporaciones que vamos a intentar demostrar en el análisis de la lengua española no sólo afectan a contenidos nominales, sino a una variada posibilidad combinatoria (como sugiere el análisis de Vera Luján, 1987), aspccto que ya pusimos de manifiesto en Cifuentes, $1999^{28}$.

28 Baker (1996: 295) nos recuerda que la incorporación de sinlagmas nominales no sólo sc da como pacientes o temas, sino tambićn como instrumentales, locativos, predicativos y otros tipos de adjuntos. Es más, la incorporación de preposiciones también está alestiguada (1996: 431-432). 
Las propiedades de la incorporación nominal son resumidas por Gerdts (1998: 92-93) en los siguientes puntos:

a) Un elemento que puede aparecer como un sustantivo, y un elemento que pucde aparecer como un verbo, se conjuntan en una sola palabra.

b) Esta palabra sirve como el predicado de la oración, y el nombre incorporado corresponde a uno de los argumentos del verbo.

c) Prototípicamente, el nombre incorporado corresponde al objeto de un predicado transitivo o al sujeto de un predicado intransitivo inactivo. En muchas lenguas, el nombre incorporado también puede corresponder a un SN oblicuo: locativo, instrumental, o agente pasivo.

d) Dos tipos de incorporación sc dan entre las lenguas (y a veces dentro de una misma lengua): la incorporación por composición, que hace decrecer la valencia de la oración, y la incorporación por clasificación, que no hace decrecer la valencia de la oración.

e) Las lenguas con incorporación por clasificación posibilitan la modificación o duplicación del elemento incorporado.

f) En los dos tipos de incorporación, cuando el nombre incorporado corresponde al núcleo de un sintagma posesivo, el poseedor asume una función gramatical — sujeto u objeto- en la oración.

En su trabajo sobre la incorporación nominal, Mithun (1984) distingue cuatro tipos de incorporación nominal, pudiendo existir cada una de estas estructuras en una misma lengua. Las estructuras de tipo I combinan un nombre con un verbo, bien por yuxtaposición, bien mediante la formación de una palabra morfológica compuesta. El resultado típico es un nuevo predicado intransitivo, y el nombre incorporado queda librc de elementos como determinantes, número y caso. Desde un punto de vista semántico, el nombre puede ser paciente, locativo o instrumental. La actividad o el estado afectado se entienden como un concepto unitario y poco destacado. El tipo Il, junto a lo dicho para el tipo I, supone cierta manipulación de los casos, por la cual algún argumento oblicuo de la oración se ve promovido a la posición, libre, del nombre incorporado. En el tipo III hay que añadir otro fenómeno, la manipulación de la estructura del discurso, a través de la cual la incorporación en el verbo de un argumento hace retroceder este último al fondo del discurso. Esta es la fase característica de lenguas polisintéticas que traen afijos verbales para sujeto y objeto, y en las cuales los sintagmas nominales no se usan mucho, siendo el predicado portador do casi toda la información. El tipo IV es la incorporación nominal clasificadora, en la que, además del nominal incorporado en el verbo, se emplea un sintagma nominal exterior que refiere de una manera más específica al argumento. A partir del análisis de más de cien lenguas diferentes, cl cstudio de Mithun muestra que los cuatro tipos forman una jerarquía de implicación; I $>I I>I I I>I V$. En cuanto al papel temático de los nombres incorporados, Mithun señala que si una lengua acepta un solo argumento para los nombres incorporados, se trata del paciente transitivo; si son dos, al anterior hay que sumar el sujeto de intransitivo, y, si son tres, un instrumental o locativo, por lo que nos encontramos con una segunda jerarquía de implicación.

No obstante, en una perspectiva más laxa del concepto, los tipos de incorporaciones fundamentales que se han establecido han sido dos: la incorporación morfológica, en la que el nombre se convierte en un morfema del verbo en cl que se integra plenamente tanto 
morfológica como fonéticamente ${ }^{29}$, y la incorporación sintáctica, en la que el nombre pasa a formar una unidad sintagmática con el verbo pero sigue conservando su autonomía morfológica, aunque pierde las características sintácticas típicas de su antigua función, poniéndose de ejemplo habitual de lenguas con este tipo de incorporación casos como el inglés a el español (hacer mención).

Aunquc Moreno Cabrera no ejemplifica la incorporación morfológica en español, demostré (como también han puesto de manifiesto Wotjak (1990) y Vera Luján (1987)) que ésta es posible, fundamentalmente bajo el mecanismo de un desarrollo a partir del sustantivo base de la verbalización (Cifuentes, 1999).

En el modelo generativista la incorporación es entendida en un sentido más restringido, así la interpretación tćcnica de Baker (1998), que afecta a la morfosintaxis de un subconjunto de casos que implican incorporación en el sentido de Mithun. En cl sentido técnico de Bakcr, la incorporación se define en términos de derivación sintáctica, en tanto que afecta a la adjunción de una categoría léxica $\mathrm{X}^{0}$ a otra catcgoría léxica $\mathrm{Y}^{0}$, una operación de movimiento que en el caso de la incorporación nominal es desencadenada por la imposibilidad dc $\mathrm{X}^{0}$ para recibir caso en la posición en que se genera ${ }^{30}$. Dicho de otra manera, la incorporación se define como un proceso que motiva que una palabra independiente scmánticamente se convierta cn un clemento integrado en el interior de otra unidad lingǘstica, resultado de la aplicación de la regla muévase $\alpha$ (Baker, 1988: 51), mediante la cual el sustantivo se desplaza desde su posición temática hacia el item léxico del verbo, $\mathrm{y}$, según el Principio de Proyección, este tipo de desplazamiento no puede alterar ni destruir la estructura temática del enunciado, por lo que siempre el elemento nominal deja de manera permanente una huella que encabeza un objeto que recibe un papel temático del verbo y satisface las necesidades de subcategorización del verbo. Evidentemente esto no supone hacer equivaler la estructura incorporada sintética con la posible paráfrasis analítica, pero tanto el modelo generativista como el que nosotros defendemos coinciden en entender las dos posibilidades como resultado de una correspondencia con una estructura o nivel conceptual previo, y como esa regla de correspondencia ha operado de distinta forma en la realización sintética y en la realización analítica, no debe extrañar que puedan diferir semántica y sintácticamente (y no sólo por las características de incorporación señaladas por Dik) ${ }^{3 !}$.

29 Las lenguas que representan este fenómeno ya fueron denominadas por Humboldt «incorporantes», como el nahual, esquimal o chucoto (Moreno Cabrera, 1991: 494). Para una historia del concepto de incorporación, vid. Sadock, 1991, quien lo remonta a Humboldt, pero E. Nansen Díaz (2000) lo sitúa cn Fray Gabriel de San Buenaventura (s. XVII), quien pudo influir en Humboldt a través de Hervás, gracias a su gramática de la lengua maya. 30 Más recientemente, Baker (1996) restringe más todavía la aplicación del término, requiriendo que la rajz del nombre incorporado esté totalmente integrada morlológicamente con el verbo.

31 Dik (1980: 42-50) señala una serie de características que presentan los fenómenos de incorporación nominal, tanto morfológica como sintáctica: a) el elemento nominal pierde su autononía morfológica y sintáctica, careciendo de determinante, ya que de otra forma, la incorporación dejaría de producirse, b) reducción del número de argumentos del predicado al que se incorpora el elemento nominal, c) el significado de un elemento verbal que experimenta incorporación nominal posce un significado de naturaleza más genérica y extensa que el verbo que no posee dicha incorporación, d) el sustantivo incorporado no posee una referencia especifica y concreta, es decir, carece de capacidad referencial, e) las construcciones con incorporación tienden a desarrollar significados idiomáticos, f) debido a los procesos de pérdida de independencia sintáctica y de conversión léxica anteriores, el sustantivo incorporado puede llegar en ocasiones a climinar sus semejanzas y vinculaciones con él mismo en sus realizaciones independientes. 
$\Lambda$ sí pues, se puede describir la incorporación en términos sintácticos, diciendo que un objeto se mueve hacia dentro de una palabra quc contiene el verbo de la oración, pero también puede concebirse en términos de morfología léxica derivativa, según la cual de un esquema predicativo verbal obtenemos un nuevo verbo con uno de los argumentos incluido como morfema ${ }^{32}$.

Por otro lado, a veces se entiende de una forma muy restringida, y no ya sólo porque parezca que debe aplicarse exclusivamente a sintagmas nominalcs, cuando nosotros también hemos hablado de incorporación que afecta a elementos prepositivos a prefijales. Por ejemplo, Gerdts (1998) distingue la incorporación de otros fenómenos, como la composición por yuxtaposición (Mithun, 1984) ${ }^{33}$, lo que supondría dejar fuera también la incorporación sintáctica, o los verbos denominales, que constituirán el fundamento de la mayoría de nuestros ejemplos ${ }^{34}$. De hecho, Sadock (1991: 82) señala que en una formación neológica denominal como verbificar (verbify), si bien podemos encontrar las mismas relaciones morfológicas que en la incorporación existente en la lengua eskimo ${ }^{35}$ (algo parecido señala también Malouf, 1999, para la lengua greenlandic), no le otorga esa denominación debido a las diferencias en las ramificaciones sintácticas de la misma. Es por ello que nosotros prefiramos partir de la propuesta de unificación de Farkas y de Swart (2003) por otro lado, a la teoría de Vera Luján (1987). Para Farkas y de Swart (2003: 59 y ss.), los elementos incorporados son argumentos de un predicado con el que se combinan por unificación, de forma que el elemento incorporado restringe uno de los argumentos temáticos del predicado sin quc sca instanciado. La unificación identifica este argumento temático con el argumento temático relevante del verbo, construyendo, entonces, un verbo complejo. Evidentemente, los elementos incorporados muestran una especial morfosintaxis que contrasta con cl mismo elemento sin incorporar, en lo que pudiera ser su esquema conceptual o paráfrasis analítica.

\subsection{Incorporación y formación de palabras}

De todas formas, estas propuestas de la teoría de la incorporación resultan demasiado limitadoras, y suelen ejemplificarse siempre en lenguas muy alejadas del español o de cualquier lengua románica. El trabajo de Vera Luján (1987), aplicado exclusivamente a la formación dc palabras, y previo a la propuesta de Baker (1988), explica muy bien todo lo que venimos comentando. Vera Luján parte de un nivel conceptual previo a su manifestación

\footnotetext{
32 Baker (1996: 280) recuerda la discusión de entender la incorporación como un fenómeno fundamentalmente sintáctico, o como un fenómeno fundamentalmente morfológico. Así, Sadock $(1980,1991)$ y Baker $(1988,1996)$ defienden la idea de que la incorpornción tiene un componente sintáctico integral, mienlras que autores como Mithun (1984), Di Sciullo y Williams (1987) o Rosen (1989) han argüido que simplemente se trata de un tipo algo diferente de composición léxica.

33 Baker (1996: 307 y ss.), cscenificando el enfrentamiento encre partidarios de la opción sintáctica frente a partidarios de la opción morfológica, seriala una serie de diferencias cntre la incorporación nominal en una lengua representativa de la misma, y la composición, eñ una lengua como el inglés.

34 Aunquic también hay otros casos de verbalización, como verbos deadjetivales, por ejemplo.

35 Sadock usa el término incorporación dc una forma muy general, refiriéndose a cualquier proceso morfológico, distinto de la clitización, que produce unidades morfológicas en las que alguno de los constituyentes morfológicos se puede demostrar que tiene realidad sintáctica independiente (1991: 100).

36 Sin querer, por ello, tomar partido por la tendencia morfalógica o por la tendencia sintácica.
} 
en una lengua, los distintos elementos diferenciados en ese nivel conceptual, al ser expresados en una lengua, tienen distinta posibilidad de manifestación, pues pueden expresarse diferenciados unos de otros, en lo que sería una formación analítica, o pueden expresarse condensados, es decir, y cn palabras de Vera Luján, sujetos a una relación de incorporación, lo cual se puede ejemplificar en llamar por teléfono vs. telefonear.

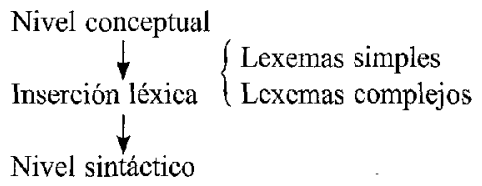

Es claro que uno de los principales problemas de esta teoría consiste en poder identificar el nivel conceptual. Sin embargo, en el caso que venimos tratando, las construcciones locales, el esquema de Talmy identifica perfectamente ese nivel conceptual, lo que nos permite entonces entender que los diferentes elementos conccptuales diferenciados por Talmy puedan venir dados en una lengua de forma independiente, o condensados, amalgamados, es decir, incorporados, según las distintas posibilidades que cada lengua permita, lo cual justifica también el hecho de que siendo la trayectoria un elemento conceptual independiente del esquema de la localización, pueda venir condensado, incorporado al verbo, aun sin ser un sintagma nominal, como parece requerir la teoría de la incorporación.

De igual forma, la teoría de la incorporación supone que el elemento incorporado restringe uno de los argumentos temáticos del predicado, es decir, que si lo implicado es la figura, ésta no debe volver a aparecer, o si lo implicado es la base, no debe manifestarse, al igual que si la incorporación es de relacionante, la base se unirá directamente al verbo, sin intermedio de preposición, porque su papel lo cumplitá un prefijo:

La luz se reflejaba en el agua (*localización de reflejos [figura]). Excarceló a los presos etarras (*localización fuera de la cárcel [hase]). Antepuso el artículo al nombre (*localización delante de [relacionante]).

Y efectivamente esto puede ser así en muchos casos, pero no siempre, pues la historia de la lengua puede ocasionar que la relación semántica entre la palabra simple y la derivada se haya pcrdido, en el sentido de que no haya transparencia alguna, o haya cambiado cl significado originario, ampliándose o de cualquier otra manera, lo que puede hacer necesario que se subespecifique el elemento incorporado:

Engrasó la puerta con aceite de oliva (*localización de grasa [figura]) ${ }^{37}$.
El barco encalló entre las rocas (*localización en sitio estrecho [base]).
Debajo de la cama subyacia una sorpresa ${ }^{*}$ localización debajo de [relacionanle]).

En ningún momento pretendemos limitar lo que pudiera ser la formación de palabras a este tipo de análisis en el nivel conceptual, pues, como muy bien dicen Santiago y Bustos (1999: 4512), cste tipo de relaciones semánticas no es suficiente para dar cuenta de toda

37 En este caso la localización es instrumental, no cumple la misma función temática que la figura. 
la complejidad de los procesos de extensión léxica. Pero, como scr̃alan por ejemplo Piera y Varela (1999: 4372), además de las relaciones formales que se establecen entre los constituyentes de la palabra compleja, es posiblc reconocer también entre ellos relaciones semánticas, y unas relaciones semánticas que no sólo están motivadas sincrónicamente, sino que estoy convencido de que las dadas en los procesos de incorporación explican, y fundamentan, los procesos cognitivos que rigen y determinan la formación de palabras, es decir, qué hacemos para crear una palabra.

Como quiera que sea, la importancia de las relaciones semánticas en el análisis de la estructura de la palabra compleja ha sido puesta de rclicve, destacando, sobremanera, las relaciones temáticas o argumentales que es posible descubrir también en su interior. Asi, se reconoce (Piera y Varela, 1999: 4386) que si el múcleo de una palabra es un predicado -como en el caso de las formaciones verbales que venimos nosotros comentando-, éste, en paralelo con las rclaciones semánticas desplegadas por las unidades sintácticas, puede llevar argumentos, es decir, complementos sclcccionados, o exigidos, semánticamente ${ }^{38}$. También, al igual que en sintaxis, el elemento que recibe papel scmántico debe estar regido por el que lo confierc, siendo los núcleos léxicos los únicos que tienen capacidad de rección. Así pues, queda plenamente admitido que una palabra derivada, o parasintética, incorpore en la propia palabra alguno de sus argumentos, sea mediante sufijo, prcfijo, composición, o de alguna otra manera. Es más, en Gramática Generativa las preposiciones, al igual que los verbos, tienen capacidad de selección semántica, es decir, estructura argumental, por lo que no nos debe extrañar, entonces, que puedan ser objeto de incorporación como si de un sustantivo se tratase.

Para Val Álvaro (1999: 4760), la posibilidad de explicar estructuras compositivas como resultado de un proccso de incorporación (caso de maniatar, por ejemplo) es clara. Es más, llegará a admitir (1999: 4755-4756) la posibilidad de interpretar algunos casos como incorporación preposicional, dada la relación existente entre prefijación y composición, y el valor relacional de algunos prefijos (sobrevolar, entremeter) ) $^{39}$.

Piera y Varela (1999: 4396) señalan explícitamente que los verbos denominales - y pone dc ejemplo los locales (encarcelar, aprisionar, embotellar) - , donde el nombre de la base se constituye como un argumento del derivado, tienen propiedades sintáctico-semánticas que manifiestan su origen compositivo, aunque me permito creer que el mismo razonamiento aplicarían a cualquier proceso de verbalización. Efectivamente, la inmensa mayoría de los verbos con incorporación local, sea de la base o de la figura (el caso del relacionante es distinto, pues se vinculará con la composición por prefijación), lo constituyen ejemplos de verbos parasintéticos denominales ${ }^{40}$, siendo el esquema de localización uno de los procesos de verbalización fundamentales (Scrrano, 1999: 4710).

38 La idea básica de Baker (1996) es que en algunas lenguas cl critcrio de asignación temática puede ser, más que sintáctico, morfológico. Esta idea tiene sus precedentes en Jelinek (1984), Marantz (1984) y Baker (1988).

39 Recordemos (Varela y Martín García, 1999: 5002) que los procesos de prefijación pueden scr sensibles a la estructura atgumental de los elementos involuerados en tales procesos, es decir, que algunos prefijos toman en cuenta los argumentos que son seleccionados scmánticamente por los predicados a los que se adjuntan.

40 Horno Chéliz (2002) así los explica explícitamente, pareciendo equiparar igualmente la relación de incorporación con la de analgama. 


\subsection{Incorporación, amalgama y verbos denominales}

Llegados a este punto, creo necesario aclarar dos cosas: a) ¿incorporación y amalgama son fcnómenos equivalentes?, b) ¿los verbos denominales locativos constituyen un tipo de incorporación?

Empezaremos por cl final: por lo que llevamos dicho hasta ahora, los verbos denominales locativos (embolellar, encarcelar, aprisionar, ensillar...) parecen constituir un ejemplo de incorporación. Ahora bien, y como scñala Labelle (2000: 215), el nombre a partir del cual el verbo cs creado puede denominarse «nombre incorporado», y por ellos los verbos denominales ser entendidos como un ejemplo de incorporación, pero no hay que entender este término para afirmar que se adopta un análisis de la incorporación a la Baker (o a la Sadock, o Mithum) para explicar la formación de estos verbos.

Aceptada, pues, la conclusión de que los verbos denominales locativos constituyen un tipo de incorporación, habrá que justificar ahora por qué hemos hecho tal afirmación, y, sobrc todo, intentar definir mejor la incorporación en su función con los verbos denominales.

Atendiendo a Mithun (2000: 917), la incorporación nominal es usada como un mecanismo básico de formación de palabras, en tanto que provee un medio dc creación de nuevos lexemas para conceptos unitarios (algo parccido a lo que también decía Baker), pero no parece aceptar la posibilidad de entender los verbos denominales como un tipo de incorporación nominal stricto sensu. Explícitamente así lo señala también Gerdts (97-98), lo cual nos conduce obligadamente al primcro de nuestros interrogantes, para saber si el fenómeno de fusión scmántica, en términos de Talmy, que se encuentra en la represcntación semántica de los verbos denominales locativos debe ser cntendido como amalgama, simplemente, $o$ como incorporación, entendiéndola entonces como equivalente a amalgama.

Según Gaytán (1998: 690), incorporación y amalgama son dos fenómenos diferentes: la incorporación tiene que ver con la cstructura interna de ciertos verbos, con los componentes que originan la estructura de los mismos, mientras que la amalgama es la fusión de dos predicados separados. Ahora bien, seguramente no logro entender la explicación que da Gaytán al respecto, pues no capto diferencia clara en su razonamiento.

Muy interesante, sin embargo, es la propuesta de Hale y Keyscr (2002), para quienes la amalgama es un tipo específico de incorporación (2002: 11), un tipo que cumple una versión especialmontc estricta de la restricción del movimiento del núcleo, según la cual la matriz fonológica (del núcleo) de un complemento reemplaza la matriz vacia del núcleo rector. No obstante, tanto la incorporación como la amalgama comparten la propiedad de adecuarse a la restricción del movimiento del nícleo y al principio de categoria vacía, al igual que comparten la propiedad de formar una palabra adjuntando el núcleo de un complemento al núcleo del elcmcnto que lo rige sintácticamente (2002: 50).

A pesar de todo ello, Hale y Keyser prefieren usar la denominación de amalgama para referirse al proceso semántico que interviene en la formación de los verbos denominales locativos, y no sólo por diferenciarse de la utilización que Baker hace del conccpto «incorporación» (aun aceptando que se trata de nociones estrechamente relacionadas, y quizás iguales), sino porque picnsan que podría haber alguna diferencia entre ambos conceptos, la cual (en caso de aceptarla) residiria en la rección, una relación que juega un papel en la restricción de los dos procesos. En la amalgama, los elementos implicados en las relaciones sintácticas cumplen la denominada complementación estricta (2002: 59), es decir, quc los 
dos se encuentran en la máxima categoría de la proyección de X, o, dicho de otro modo, que los especificadores, o los determinantes, no se amalgaman, ya que la proyección categorial de los especificadores nunca se hermana, nunca se encuentra cn el mismo nivel, con la del potencial objetivo, regido por V. La incorporación, por otro lado, no está sujeta a este requerimiento: un verbo no puede amalgamarse con el especificador de su complemento, aunque si incorporarse ${ }^{41}$. La explicación a este hecho, en el modelo generativista, es que la amalgama no es un proceso, es decir, no es una operación de movimiento. En su lugar, el fenómeno que pucde ser entendido bajo ese nombre es, simplemente, una relación de ligamiento que se da entre los rasgos semánticos de un verbo y los rasgos del núcleo nominal de su complemento ${ }^{42}$. Esto, a su vez, es resultado de una relación de selección entre cl verbo y su complemento. La selección ocurre entre cl verbo y el núcleo de su complemento, pero la selección no es una relación que se de entre el verbo y un especificador que puede estar presente en el complemento del verbo. Por contra, la incorporación se ve determinada por la rección, una relación que subsume la selección pero no se limita a ella: ya que el núcleo rige al especificador de su complemento, no hay barrera alguna para incorporarlo desde esa posición (2002: 103).

Así pues, tanto desde cl punto de vista de la tipología linguística, como desde el modelo epistemológico generativista, hay razones válidas para difcrenciar amalgama de incorporación, aun accptando la estrecha relación entre ambos fenómenos. No obstante, y como mi trabajo no es tipológico, ni está marcado por una orientación generativista, seguiré usando indistintamente ambos términos para referirme al proceso existente en la represcntación semántica de los verbos denominales locativos, pues parto de un marco más amplio que, creo, me lo permite, aun sabiendo que si concreláramos algún detallc desde el punto de vista generativista, o si tuvićramos que comparar tipológicamente la formación denominal románica con otros procesos de incorporación, deberíamos diferenciarlos. Y en cuanto a la posibilidad de diferenciarlos por niveles (la incorporación sería morfosintáctica, y la amalgama, léxico-conceptual), tampoco nos servirá de mucho, pues en muchas ocasiones estamos utilizando el concepto de «incorporación conceptual».

\subsection{Verbos denominales locativos}

Alvar y Pottier (1982: 347) señalan que, en el caso de los verbos parasintéticos, son posibles dos modelos en su formación; cl de la relación básica de posesión, y el de la relación básica de situación. Cada uno de estos casos viene ejemplificado de la siguiente forma: si decimos Juan engrasa su coche estamos emitiendo un enunciado semejante a Juan pone grasa alen su coche, es decir, el coche tiene grasa. En cl otro caso; como Juan embarca a Carlos, tendríamos una equivalencia a poner en el barco, pudiéndose producir, en otras circunstancias, ejemplos válidos para ambas referencias, según sea el contexto en el que se encuentren.

41 Hale y Keyser intentan demostrar este hecho con ejemplos de la lengua hopi, lo cual no es exactamente una relulación a Mithun, pues ella scriala que determinantes y modificadores en general to es que no se puedan incorporar, sino que normalmente no lo hacen (2000: 917).

42 Esta es la razón, aunque no sé si válida, que me permile seguir manteniendo la traducción de confiation por amalgama, pues aunque en los últimos años, desde el modelo gencrativista, parece haberse propuesto fusión, me parece que puede seguir aceptándose mi primera traducción como amalgama, tratándose, por otro lado, de un nombre más técnico y cspecializado. 
Creo que los dos maestros hispanistas vislumbraron claramente el proccso conceptual de formación verbal mediante incorporación conceptual, ejemplificándolo con dos casos paradigmáticos: incorporación de la base: embarcar, e incorporación de la figura con el relacionante: engrasar. Siendo los dos, procedimientos locales de incorporación conceptual. Evidentemente son posibles otros procesos de incorporación conceptual, pero lo cierto es que los locales tienen un papel fundamental en la formación y creación de verbos.

\subsubsection{Poserión y localización}

La idea de relación básica de posesión y relación básica de localización ha sido utilizada profusamente como mecanismo explicativo. Así, Kiparsky (1997: 484-485) la utiliza para diferenciar los denominados verbos locatum y los de localización (engrasar y embarcar, respectivamente), que serían identificados por una relación de posesión o de localización en el nivel de la forma semántica ${ }^{43}$.

La denominación de verbos locatum y de localización, de gran éxito en el generativismo, parece provenir de Clark y Clark (1979), y viene aplicada a aquellos verbos denominales cuyos nombres base se encuentran en caso objetivo en oraciones que describen la localización de una cosa respecto de otra, en el caso de los verbos locatum (1979: 769), como engrasar, tal y como demostraría, según Clark y Clark, la relación dada entre engrasar y el nombre grasa en la paráfrasis analítica pertinente:

Juan engrasó la puerta.

Juan hizo algo que provocó que [la puesta tuviera grasa sobre ella].

Pero Clark y Clark dejan muy claro que las hipotéticas oraciones base, según ellos, describen localizaciones. En el caso de los verbos de localización, los nombres base se encontrarían en caso locativo (1979: 772):

Kenneth embarcó al perro.

Kenneth hizo algo que provocó que [el perro estuviera en un barco].

Así pues, las primeras diferencias entre cstos dos tipos de verbos denominales estribaban en la implicación de los casos objetivo y locativo, según la terminología fillmoriana de la época, y el tratamiento composicional semántico-generativista de los mismos. Es por ello que, de esa manera, no nos debe extrañar que Kirschner (1981), sin utilizar la terminología anterior, diferenciara los dos tipos de verbos denominales aludidos por la implicación de los casos objetivo y locativo igualmente (1981: 46 y ss., 87 y ss.).

Dejando los aspectos semántico-generativistas aparte, es preciso señalar que la denominación de locatum y localización, y la necesidad de diferenciación de los dos tipos de verbos, ha tenido un cierto éxito en la escuela generativista. De hecho, su explicación de los verbos locatum y locativos viene a ser muy similar a la planteada por la antigua semántica generativa, lo que ha ocasionado también no pocas críticas.

43 Para una comparación del concepto de forma semániica con los niveles estructurales de lengua y conceptualización en el cognitivismo y el generativismo, vid. Cifuentes, 1994: 96 y ss. 
Basánđose en el análisis do Rappaport y Levin (1988), Pinker (1989) propone que los verbos de localización, como embarcar, tienen una estructura conceptual como la siguiente:

\section{CAUSA [Y ESTAR EN $\left.{ }^{44} \mathrm{Z}\right] / \mathrm{X}$ CAUSA [Y ESTAR FN BARCo]}

Por el contrario, los verbos locatum, como engrasar, son derivados léxicamente por medio de un proceso de subordinación léxica, lo que supondría una estructura conceptual como la siguiente:

\section{Causa [Z ir at. estado] por medto de [X CaUsa [Y ESTAR EN Z]] / \\ $\mathrm{X}$ causa [Z IR al estado] por Medio de [X calsa [GRasa estar en Z]]}

Una propuesta distinta es mantenida por Jackendoff (1990), quien, en vez de postular una diferencia fundamental entre verbos locativos y locatum, propone que comparten la misma representación, siendo su diferencia que los locativos tienen un argumento meta incorporado, y en los locatum es un tema el incorporado.

Labelle (2000) propone que tanto los verbos que incorporan el tema (locativos), como los que incorporan meta (locatum), tienen una estructura léxico conceptual en la que cl nombre incorporado es un predicado que describc cl estado final de una entidad, siendo esta entidad proyectada a la posición de objeto directo, donde es hermana de su sujeto de predicación. Esta propuesta permite predccir que, cuando el nombre incorporado se interpreta como localización, el objeto directo será tema (embarcó a su prima), y cuando el nombre incorporado es tema, el objeto directo será la localización (engrasó la puerta), lo que, en cierta forma, sería volver a la idea primera de relación de situación y relación de posesión.

Según Hale y Keyser (2002), verbos locativos y locatum tendrían la misma estructura sintáctica léxica, consistiendo su diferencia cn las propiedades semánticas fundamentales de la preposición afectada. Las preposiciones tácitas de los dos tipos de verbos (embarqué el crudo>puse el crudo en/dentro de el barco, engrasé la escopeta>puse grasa en la escopeta>la escopeta tiene grasa) corresponden respectivamente a un valor locativo o posesivo (2002: 19), lo cual vcnían explicándolo como relación de coincidencia terminal (en el caso de los locativos), que se da en su paráfrasis analítica (puso el crudo enidentro de/sobre el barco) o relación de coincidencia central, visible en la paráfrasis analítica (puso la puerta con/de grasa). De esta forma, esta hipótesis tiene la ventaja de que ambos tipos de verbos tienen la misma representación léxica, con la diferencia de lexicalizar el clemento continente (reflejado en el hecho de que el elemento léxico amalgamado en el verbo, y al cual da origen, presenta el papel de localización) para los verbos locativos, o cl clemento contenido, para los verbos locatum (al presentar el elemento léxico el papel de tema) ${ }^{45}$.

44 Adaptamos esta estructura y la siguiente a los usos estativos.

45 En una oración como el libro está en la mesa, es una propiedad fundamental de en (o cualquier otra válida en cstc contexto) que su complemento se entienda como la localización, mieniras que el papel de tema se asocia con el argumento que satisface el requerimiento de especificador de la preposición (el libro). En cl caso de cont, en su sentido (temporal) posesivo (vi a.John con un coche nuevo), cstas relaciones están invertidas: el objeto de la preposición es entendido como tcma dc la relación posesiva, mientras que el especificador (John) es comprendido como cl poseedor (temporal) (Ilale y Keyser, 2002: 19). 
Horno Chéliz critica que cl elemento nominal que sirve de base para los verbos locatum no puede aparecer en posición de especificador (2002: 428 y ss. $)^{46}$, debido a que, entonces, el proceso se vería bloqueado. De esa forma, entiende que la relación entre el predicado locativo y el predicado locatum se puede expresar de dos modos distintos: por medio de un predicado locativo propiamente dicho, o por medio de un predicado de posesión, caso este último de los predicados nominales locatum, interpretándose entonces como ' $X$ causa que $Y$ tenga $Z$ '. Por tanto, todos los predicados denominales se formarian mediante la lexicalización del argumento $Z$, gencrando dicho argumento los predicados denominales locativos dentro de un SN locativo (por ejemplo, emharcar presentaria la base léxica nominal barco en el interior de un sintagma preposicional (SP), y recibiría el papel de localización). Sin embargo, los predicados denominales locatum presentarian dicho argumento en el interior de un sintagma verbal (SV), de tipo abstracto, que establcccría la relación de posesión (por ejemplo, en engrasar, la base léxica grasa aparece dentro del sintagma verbal, recibiendo el papel de tema).

Al presentar un SP abstracto lexicalizado los predicados denominales locativos, el SP aparece previsto en la representación léxica de estos predicados, lo que le conferiría una naturaleza argumental: hemos embarcado al jefe en una patera. Por el contrario, al lexicalizar los predicados denominales locatum un predicado no preposicional, pues no conceptualizan una relación de localización, no preveen la aparición de un SP como argumento del predicado, pero es posible que aparezca un adjunto preposicional que recupere el argumento lexicalizado en el predicado verbal: hemos engrasado la puerta con aceite. Horno Chéliz insiste en que la diferencia entre los dos tipos de predicados sería mínima (2002: 432-433), pucs supone lexicalizar el mismo evento complejo de realización, planteándose una relación entre un elemento continente (locativo) o contenido (locatum) en el segundo subevento, y residiendo la difcrcncia en el nivel originario de la estructura léxico-conceptual en la perspectiva desde la que se lexicaliza dicho evento, bien como localización, bien como posesión. Esta distinta perspectiva tendría importantes consecuencias sintácticas y semánticas, por ejemplo la aparición, o no, de un SP en posición argumental: embarcar en la patera vs. engrasar la puerta con aceite. Sin cmbargo, en el nivel de la estructura léxico conceptual, ambas estructuras estarian relacionadas, to cual permitiría explicar que, en determinadas circunstancias, un mismo predicado denominal puede ser interpetado como locativo o como locatum, así encalar, por ejemplo, según el elemento lexicalizado (cal, en este caso) sea lo suficientemente permeable para permitir ser considerado contincnte o contenido (blanquear con cal una cosa vs. meter en cal).

Mateu también revisa la teoría de Hale y Keyser, y critica las nociones de relación de concidencia terminal y relación de coincidencia central, relacionándolas con las nociones léxico-aspectuales de lelicidad y atelicidad respectivamente. Según Mateu (2001a: 229; 2002: 13 y ss.), debe establecerse que tanto los verbos locativos como los locatum contienen la relación de coincidencia terminal que puede asociarse a los verbos télicos de cambio de estado. Así, partiendo de la idea de Labelle (2000) de que el nombrc incorporado, tanto en los verbos locativos como locatum, identifica semánticamente el estado final del proceso, es-

46 Las críticas de Horno Chéliz parecen adecuadas desde el paradigma generativista, pero, desde un punto de vista no generativista, la argumentación para explicar la agramaticalidad de construcciones utilizadas cn su argumentación, como *embaldosar el coche sería otra, y muy sencilla de entender pragmáticamente. 
tablece que verbos locativos y locatum deben scr considerados verbos causativos de cambio de estado, cuya telicidad viene determinada por la presencia de una relación de coincidencia terminal abstracta (2001a: 235; 2002: 20).

Según Hale y Keyser, como ya hemos dicho anteriormente, los verbos locatum manifiestan una relación de coincidencia terminal, pero Mateu demuestra que estos predicados ticnen un comportamiento télico en catalán (y en español, añadimos nosotros), y, a diferencia de Hale y Keyser, la rclación de coincidencia central sólo puede darse en predicados atélicos:

Engrasó la puerta [*durantelen cinco segundos].

Juan va a estar con Maria /durante/"en cinco segundos].

Juan va a empujar el carro [durante/*en cinco segundos].

Por otro lado, como los verbos locativos contienen una relación de coincidencia terminal, se cspera que se comporten como los verbos locatum:

\section{Embarcó al niño [*durantelen cinco segundos]}

En definitiva, y concluyendo el trabajo de Mateu, ya que los verbos locatum se comportan como verbos de cambio de estado - con respecto a los análisis llevados a cabo por Mateu relativos a la formación media y las prucbas de predicación secundaria--, se puede derivar la hipótesis ya señalada de que las dos clases de verbos suponen una rclación de coincidencia terminal abstracta, que está en el origen de la telicidad léxica ${ }^{47}$.

\subsubsection{Figura y base}

Von Heuringen y Schwarze (2002), en su análisis de los verbos denominales italianos con sentido ablativo, tipo excarcelar o descremar en español, establece la identificación entre los verbos locatum y locativos y los verbos de figura y base, en un scntido muy similar al que nosotros mismos hemos venido manejando en trabajos anteriores, fundamentalmente dedicados a las construcciones de movimiento, lo que les permitirá, entre otras ventajas, no sólo mantener el mismo tipo de estructura conceptual para los dos tipos de construcciones, variando su diferencia según el elemento sea perfilado como figura o como base (y por ello como tema - objeto localizado - y locativo - objeto localizante - respectivamente), sino también explicar por qué unos verbos que se basan en determinados lexemas se materializan fundamcntalmente como locatum y otros como locativos, pues el contraste entre figura y base asi lo explica ${ }^{48}$, to que evita, y justifica, clasificaciones como la de Clark y Clark (1979: 791).

Efectivamente, toda la cxplicación generativista, aunque muy válida metateóricamente, nos parece complicada en exceso. Me parece adecuado partir de la misma estructura con-

47 Aspecto éste que es también aceptado por Harley (2001).

48 En el sentido de Talmy (1983), pucs el objeto que funciona como figura suele ser más pequeño, movible, geométricamcnte más simple, más destacable y más reciente en la escena o en el conocimiento, micntras que el objeto que funciona como base es conocido en cuanto a sus características espaciales, es más estable y permanente en su localización, mayor, parece tener una mayor complcjidad geométrica, actua como un fondo cognitivo, y es anterior en la escena o en la memoria. Vid. También Vandeloise (1986) y Schulze (1987) al respecto. 
ceptual para las construcciones locatum y locativas, pero entendemos que es posible otra explicación más satisfactoria para dar cuenta de su vinculación con la estructura manifestativa de las mismas. Entiendo que el esquema del que hay que partir es el de la estructura conceptual de localización de Talmy, pues conceptualmente considero las construcciones locatum y locativas como estructuras locales, y si bien en su manifestación las construcciones locatum pueden tener un valor posesivo, ese valor posesivo lingüístico es derivado del valor local conceptual. En ese sentido, preferimos utilizar el modelo de Talmy, pues, entre otras razones, no nos obligará a diferenciar los causativos adlativos de los ablativos, teniendo que incorporar un caso meta o un caso origen (cargar vs. descargar) según las circunstancias.

$$
\begin{aligned}
& \text { Figura ------- Localización ------ Trayectoria ------- Base -.--..- [Causa/Manera] } \\
& \text { (Situación/Desplazamiento) }
\end{aligned}
$$

En el caso de los verbos locativos, nuestro análisis, paralelo al que ya establecimos con los verbos de desplazamiento, coincide con la propuesta generativista, en tanto que son producto de la incorporación o amalgama de la base local. Diferimos, no obstante, en las razones por las cuales linguíísticamente puede aparecer un SP argumental (hemos embarcado al jefe en una patera), pues no pensamos en explicaciones sintácticas (lexicalización de un SP abstracto), sino pragmáticas: la indeterminación del SN base de la derivación verbal puede hacer necesario, pragmáticamente, que haya que especificar éste, según las nccesidades comunicativas en cada caso, cstableciéndose, normalmente una relación de hiperonimia entre el elemento lexicalizado en el verbo, y el núcleo del SP argumental (barco-patera), independientemente del hecho de que el propio significado verbal pueda haberse extendido o ampliado a partir de la localización inicial (encasillar: *localización en casillas > 'clasificar distribuyendo en los sitios correspondientes').

En el caso de los llamados verbos locatum, creemos que es también necesario partir del esquema general de localización, y no ya porque las paráfrasis habituales alternativas a ejemplos como engrasa la puerta, sean ponle grasa a la puerta, esquema local, siendo la puerla tiene grasa interpretación derivada de la anterior ${ }^{49}$, y proponer $x$ causa que la puerla tenga grasa me parce que perfila la escena de una manera que desvirtúa el punto de vista de la misma.

Por otro lado, limitar a una relación de posesión el vínculo establecido entre figura y base en un ejemplo como engrasó la puerta [figura(grasa)-poseída-fondo(puerta)] me parece demasiado pobre.

Prueba, sintáctica, de que los verbos locatum establecen una relación de localización en su estructura conceptual, puede ser el hecho de que hay muchos verbos locatum que incorporan en su formación un prefijo local que funciona como relacionante, en el sentido de que ese relacionante (trayectoria) indica, dc un modo más o menos Iransparente, la relación local entre figura y base, independientemente del hecho de que el verbo pueda haber evolucionado, más o menos, en su significado.

49 Como ya comentamos, la estructura conceptual no la queremos hacer derivar de discutibles paráfrasis c interpretaciones en el plano lingüístico, no conceptual. 
Subrayar las palabras: *loc. raya (figura) + so las palabras.

Sopalancar el coche: "loc. palanca (figura) + so el coche.

Sobrehilar la sábana: *loc. hilo (figura) + sobre la sábana.

Engrasar la puerta: *loc. grasa + en la puerta.

Quiero decir con esto que, al igual que hay ejemplos de locatum que incorporan la trayectoria al verbo, hay otros ejemplos de locatum en los que el relacionante está totalmente implícito, pero la estructura conceptual sigue siendo local, y normalmente concebida como un esquema de contencdor y, por ello, parafraseable por en. Lo cual nos explicaría también por qué, en español, son posibles verbos locatum que ticnen dos formas, una con el rclacionante explícito (enalbardar, enmechar; enfipiar) y otra con el relacionante implícito (albardar, mechar, ripiar).

De igual forma, Hale y Keyser (2002: 29) señalan que los verbos locativos y locatum sólo tienen usos transitivos, pero en español también son posibles ejemplos intransitivos: enraizar, arraigar. Asimismo, la posibilidad de que la figura aparezca como sujeto, con una construcción pronominal, también puede ir en la misma línea de demostración:

\section{El limo se sedimentó en el fondo del mar.}

La luz se reflejaba en el agua.

Por otro lado, esta misma estructura conceptual local es la que nos permitiría explicar otros casos como ondear, muronear, domiliar, en los que la formación verbal no es local: ondear no se origina a partir de *localización de ondas, ni el resto, sino de *hacer ondas, estructura factitiva. Ahora bien, la argumentalidad del SP local es posible explicarla porque dicha estructura se perfila desde un punto de vista local, haciendo intervenir una relación local entre figura y base (explicita), aunque el verbo se originara factitivamente, pero la construcción es local, justificando así cl SP.

Así pues, por las razones expuestas, concluyo que la estructura conceptual de los verbos locatum debc ser obligadamente local, lo cual no quiere decir que la realización lingüística de dicha estructura deba ser entendida como local.

La explicación de la interpretación posesiva que puede tener una construcción con verbo locatum no creo que haya que buscarla en la estructura conceptual, que es local, sino en la estructura lingüística. No pretendo tampoco señalar, como comenté en la introducción, una explicación de tipo localista, en el sentido de hacer derivar el valor posesivo de los valores locales y existenciales ${ }^{50}$, como también afirma Langacker (2004).

50 La relación entre posesión y existencia, parece deducible de la propia relación entre cxistencia y localización: et libro es de Juan. La localización implica la existencia, ya que si somos capaces de localizar algo es debido a que ese algo existe.

La posesión tiene también claramente que ver con la localización, ya que lo poseído está localizado cn el poseedor. Hay una serie de expresiones que presentan el estado del objeto como neccsidad interior, como disposición del sujeto, de modo que el elemento que manificsta tal estado aparece como base de la localización, mientras que la disposición, el estado, aparcce como fenómeno localizado en el objeto. Según M. Manoliu (1985: 95), el francés, español, portugués o italiano sujetivizan la base de la localización, ya se trate de un estado físico o psíquico, y el verbo copulativo recibe la forma de tener. Ahora bien, como señala Moreno Cabrera (1992: 570 y ss.), al ser el lugar de localización frecuentemente un ser animado, esto ocasiona que, en muchas ocasiones, se conciba como un receptor o un bencficiario. Además, la relación entre el poseedor y lo poseido no necesariamente es accidental, sino que puede ser esencial: lo poseído puede ser parte esencial del poseedor. Según Moreno Cabrcra (1992:573- 
Una oración como Juan engrasa la puerta no perfila una relación posesiva, si acaso la presupone, pues al actuar Juan sobre el objeto puertu, sirviéndose del medio grasa, logra un cierto resultado sobre puerta, pudiendo entenderse entonces, de alguna manera, quc gracias al estado resultante de la acción, la puerta, cn cierta forma, posee el medio.

La explicación a la interpretación posesiva de la oración anterior creo que puede descansar en que posesivos y locativos comparten una caractcrización conceptual abstracta basada en la habilidad del punto de referencia que diría Langacker (2004: 112). La habilidad del punto de referencia es nuestra capacidad para invocar una entidad conccbida como un medio de establecer contacto mental con otra, es decir, mentalmente se accede a una entidad a través de otra (Langacker, 2004: 87): el conceptualizador primero dirige su atención a una entidad que sirve como punto de referencia, según cl cual evoca un conjunto de entidades asociadas, colcctivamente denominado su dominio, uno de los cuales es el objetivo. Una relación de punto de referencia no es otra cosa, entonces, quc un asunto de acceso mental secuenciado, donde al dirigir la atención al punto de referencia hace posible entonces dirigir la atención al objetivo.

Intentando decir las cosas un poco más claro, estableceremos que esta ligazón abstracta es lo que permite a las construcciones locativas ser usadas para la posesión, y al revés: en el caso de engrasa la puerta, la interpretación posesiva vicne dada por la relación melonímica, pues, como señalamos más arriba, la relación de posesión que es posible establecer entre grasa y puerta viene dada como consecuencia de una acción.

\subsubsection{Construcciones analiticas y sintéticas}

Ha sido muy criticado, y con razón (Serrano Dolader, 1995: 107 y ss.; 1999: 4710 y ss., por ejemplo), el hecho de intentar aprovechar las evidcntes relaciones entre formaciones analíticas y sintéticas, en casos como los que estamos estudiando (engrasar-*poner grasa elen; embarcar-* poner en el barco), como mecanismo explicativo, cn el sentido de pretender que la construcción analítica cs la base a partir de la cual se crea el verbo parasintético (aspecto éste que en modo alguno hemos pretendido, pues las dos posibilidades, sintética y analítica, deben entenderse como resultado de una correspondencia con una estructura o nivel conceptual previo, pudiendo por ello diferir sintáctica y semánticamente). De

575), esto no ocurre en la localización, donde el lugar de localización poscc una relación mucho menos íntima con lo localizado. Aun así, existe un tipo de posesión más parecida a la localización, en la que lo poscído no cs parte esencial del posccdor: la posesión alienable, en la que la relación es de carácter extrínseco, esporádico u ocasional, denominando posesión inalienable cuando cl vínculo es intrínseco, permanente y constante. En cada lengua se establece de modo idiosincrático qué posesiones se consideran alienablcs y qué otras se consideran inalienables. En español to normal es no marcar la inalienable y marcar la alienable (tener: in alienable, poseer: alicnablc. Pcro lo importante en cstos casos no es la relación real que exista entre los elementos, sino cóno se conciba esa relación.

Si bien la lingüística cognitiva —y toda la escuela fenomenológica-parecen apoyar las tesis localistas (en e] sentido de que las expresiones espaciales son más básicas, gramatical y semánticamente, que los diversos tipos de expresiones no espaciales, sirvicndo de plantilla estructural para otras expresiones, ya que la organización espacial Liene una importancia máxima en el conocimiento humano), esto no quiere decir que afirmemos su sistematicidad: que nos sirvamos de transposiciones espaciales para materializar otras experiencias no quiere decir que ello se haga sistcmática y obligadamente, sino que hay una tendencia. Igualmente, esa tendencia es de nuestras experiencias físicas, pero estas experiencias no son exclusivamente espaciales (Cifuentes y Llopis, 1996; 19-20). 
igual forma, el intentar valorar el prefijo de estas construcciones según sea su función en la correspondiente paráfrasis explicativa analítica, puede levar a dobles interpretaciones: enmarcar: *poner en un marco vs. *poner un marco a, aparte del hecho de que pueden producirse significados diversos: encastillar: *encerrarse en un castillo vs. *fortificar con castillos un pueblo, así como que este tipo de mecanismos explicativos no son aplicables al análisis de todos los verbos así crcados. Sin embargo, no es éste el planteamiento que estamos utilizando en nuestro trabajo, pues a) no pretendemos que la construcción analítica sea la base a pertir de la cual se produce una formación sintética: la construcción analítica y la sintética están en un mismo nivel, pues ambas dependen de una estructura conceptual común, quc puede representarse léxicamente por medio de estructuras simples (analiticas), o compuestas (sintéticas), si hacemos intcrvenir algún proceso de incorporación conceptual, como expusimos más arriba ${ }^{51}$. b) Las dobles interpretaciones del tipo de enmarcar, $\mathfrak{u}$ otras más difíciles de resolver, sólo quiere decir eso, que hay que refinar el análisis hasta llegar a algún tipo de conclusión que pueda ser legítima. Por otro lado, que enmarcar el cuadro pucda ser describible én principio como *(localización + figuru-marco + relacionante ubi) el cuadro o como *(localización + relacionante ubi + base-marco) el cuadro, deja claro que se trata de una incorporación conceptual de un proceso de localización posicional, pudiendo variar si la base transparentada funciona como figura o como elemento localizante, pero resolver este asunto no puede hacerse exclusivamente desde las paráfrasis, pues habrá que considerar el valor de éstas así como los paradigmas tipológicos estructurales cn que se insertan, y todo ello desde la perspectiva de la realidad conceptualizada y manifestada ${ }^{52}$ c) En cuanto a la posible diversidad de significados, Lipo se encastilló en un risco o encastillaron el pueblo, hay que tener mucho cuidado en no confundir el funcionamiento usual de la lengua con un problema. Quiero decir que, en el cjemplo propuesto por Serrano Dolader, la incorporación conceptual es la misma en ambos casos:

\section{Se encastilló en un risco: \\ *localización + relacionante-ubi + base-castillo $]+$ figura-se + en un risca (especifica- ción ubi). \\ Encastillaron el pueblo: \\ *llocalización + relacionante-ubi 1 base-castillo] + figura-el pueblo.}

51 Ha sido muy criticada la tcoria de Hale y Keyser al pretender equiparar la formación sinlética (locativo y locatum) con la formación analítica (paráfrasis explicativa), llegando a emparentarlo con las propucstas de la semántica generativa (Pullum, 1996; Jackendoff, 1997: 231 y ss.; Fodor y Laporc, 1999) -propuestas que nosotros también hemos incorporado en nuestro análisis do los verbos locativos y locatum. Para una respuesta a las mismas debe verse Matcu (2002: 63-75).

En cuanto a las críticas de Fodor y Lapore relativas a los límites a la productividad de las formaciones locativas y locatum (he gave a trim a bush pero *he bushed a trim, she gave her money to a church, pero *he churched her money), debemos comentar dos cosas: a) plantearnos, en el campo de la formación de palabras, lo que no hay, es muy complicado, pues no sabemos si en un futuro lo podrá haber (piénsese, por ejemplo, en cl verbo ticar, con un uso inexistente hace treinla años y, en la actualidad, muy difundido). b) La aceptabilidad, o no, de la formación dependerá, como sen̂ala Vera Luján (1987: 166 y ss.), de que sintetice relaciones prototípicas, es decir, comunes a una comunidad, las más relevantes desde el punto de vista de las necesidades comunicativas de una comunidad dada, aquellas especialmente presentes, habituales, necesitadas, en suma, como puntos de referencia de una colectividad.

52 *En qué marco pusiste el cuadro? -Base.

¿A qué cuadro le pusiste marco? -Figura.

* ¿A qué marco le pusiste cuadro? -Base.

¿trr qué cuadro pusiste el marco? -Figura. 
La diferencia entre ambas construcciones viene dada no por la incorporación conceptual efectuada, sino por el término origen de la formación, castillo, que puede entenderse como «edificio fortificado», o, metafóricamente a partir de los rasgos protección, defensa, etc., como «cualquier lugar o paraje que sirve de defensa y protección». Pero esto es algo usual y quc puede configurar incluso incorporaciones diferentes para una misma forma ${ }^{53}$ : acostar, entre otras cosas, puede significar uechar o tender (a uno) para que descanse, esp. en la cama» o «llegar a la costa», ambos significados son producto de una incorporación conceptual distinta, y, además, se dan con una base distinta, mejor dicho, la base formalmente es la misma, costa, pero sus significados son distintos. Así, costa en tanto «costillas, espalda de una persona), produce la incorporación de *localización + manera, la manera viene determinada por la posición física de la basc que transparenta el término; mientras que cuesta en tanto «ribera u orilla del mar» ocasiona *desplazamiento + relacionante ${ }^{54}+$ base-costa.

Estamos de acuerdo, no obstante, cuando señala Dolader (1995: 111) que este tipo de explicaciones pueden ser útiles para las formaciones con prefijos espaciales, y claro que este tipo concreto de explicaciones no son aplicables al análisis de todos los verbos parasintéticos o derivados, pero se podrán ulilizar otros tipos de incorporaciones conceptuales, pues esta idea es fundamental como mecanismo explicativo de la formación de palabras (Vera Luján, 1987; Baker, 1988)

Así pues, cognitivamente es resaltable el hecho de que muchos significados de verbos que incorporan algún tipo de amalgama, han desarrollado nuevos significados motivados metafórica o metonímicamente desde la condensación originaria. De igual forma, es cognitivamente importante el hecho de que aunque muchos verbos no desarrollen lingüísticamente esquemas locales estativos, desde un punto de vista conceptual sí lo hacen, aunque luego expresen léxicamente esos contenidos estativos en forma de incorporación conceptual.

Las amalgamas de Talmy, por ello, al igual que las incorporaciones, debemos verlas en ese paso de la estructura conceptual a la estructura sintáctico-semántica, paso que puede acarrear que algunos de los elementos individualizados conceptualmente se manifiesten lingüísticamente condensados o amalgamados en una sola forma. Dentro del conjunto de amalgamas que Talmy señala, y que podemos aplicar a los verbos estativos en español, debemos mencionar diversos tipos. El primero ya lo hemos comentado en el apartado anterior, y son los verbos de manera de posición, en los que el verbo expresa tanto la ubicación como la manera de la misma, lo que se traduce en una posición o postura determinada, además de los verbos situativos, es decir, de aquellos que no son producto de ninguna amalgama o, como Talmy diría (2000: 62), que no combinan la localización verbal con ningún otro componente semántico. Pcro distinguiremos tres posibilidades más, en lo que va a ser el tercer tipo de verbo local estativo, el verbo con incorporación local: incorporación de la base, incorporación de la figura e incorporación del relacionante.

\footnotetext{
53 Vid. Montoro Montalbán \& Cifucntcs Honrubia (1996) para una cjemplificación al respecto.

54 Incorporamos la idea de relacionante no exactamente porque acostar incorpore una $a$ procedente del direccional latino ad, sino porque lógicamente lo necesita, ya que un lugar no puede venir identificado por sí mismo, sino en relación a otro lugar, siendo un uso prepositivo el término de esa relación, y si dicha relación no aparece sintácticamente será, en el caso que venimos analizando, porque viene condensada en la formación verbal
} 


\subsection{Localización + base}

El primer aspecto que hay que considerar dentro de este tipo dc incorporación, e independicntemente de la cuestión previa, que es poder determinar con precisión la etimología del verbo, de forma que se transparente claramente la posibilidad de incorporación, es si se trata de una formación románica o latina. Las formaciones latinas, aunque expresarán el mismo tipo de contingencias que las románicas (cambio de significado, necesidad de subespecificación de la base, etc.) no lás vamos a considerar, pudiéndonos encontrar con una cantidad ingente de verbos que conceptualmente expresan este tipo de amalgama local:

\section{Cargar/carricare - "poner en un carro. \\ Ubicaríbicare - *poner en un lugar. \\ Situar/situare - *poner en un sitio.}

Es necesario señalar que el grupo de estos verbos que estamos tratando son aquellos que, pudiendo entender la base dada en el propio verbo al estar incorporada, desarrollan, o tienen la posibilidad de desarrollar como complemento obligatorio, otra base local, que es entendida como subespecificación de la incorporada cn cl verbo ${ }^{55}$ :
Se embarcó en una goleta desaliñada / Localización en barco > en una goleta
El barco encalló entre las rocas / LLocalización en paso estrecho > entre las rocas.
Lo encasillaban siempre en los peores papeles / * Localización en casillas $>$ en los peores papeles.
Se enredó entre las zarzas / 'Localización en red > entre las zarzas.

Parece congruente pensar quc muchos de estos verbos puedan haber cambiado el significado original que dio paso a la formación, ampliando en alguna manera el significado por lo general. Por ejemplo, enredar no es exactamente *localización en réd, ni encasillar * localización en casillas. La extensión del significado a partir del complemento de lugar implicado en la incorporación parece obvia.

No son extraños los casos en los que el verbo especifica también, con la amalgama, el tipo de relación local que señala el objeto localizantc o base, que normalmente suele generalizarse con en pero que puede tener otros valores: soterrar: *localización bajo tierrat.

\subsection{Localización + figura}

Dentro de los verbos que incorporan la figura de la localización en el semismo verbal, debemos distinguir aquellos que únicamente localizan la figura, de aquellos otros que ade-

55 Otra cuestión es que el prefijo pueda ser entendido como trayectoria, lo que daría lugar, entonces, a la analgama, en térninos de Talmy (2000: 61-62) de localización + dos componentes: base y trayectoria, en este caso. Sin embargo, y siendo plenamente válida esta propuesta, vamos a tratar unitariamente los casos de amalgama sólo de base y los casos de amalgama de trayectoria y base, dando un cierto senticio totalizador a la idea de complemento de lugar que la base expresa (incluida la trayectoria).

56 Resulta obvio señalar que la difcrenciación que hemos establecido entre direccionales interiores y posicionales cs muy dificil de precisarla, si es que se puede, en el nivel conceptual de las incorporacinnes conceptuales. Es por ello que si no encontramos pruebas evidentes de direccionalidad interior, considcremos a la formación verbal resultado de una localización posicional. 
más de la figura señalan la relación local entre ésta y la base, que puede estar explícita en forma de prefijo $0^{57}$ :
Engrasar: *localización de grasa en: engrasó la rueda/*puso grasa en la rueda.
Socalzar: "localización de calza bajo: socalzó la pared/* puso calzas bajo la pared.
Subrayar: *localización de raya bajo: subravó la palabra / "puso rayas bajo la pala- bra.
Enraizar: *localización de raíces: enraizó en Alicante / *puso raices en Alicante.

Fs preciso señalar que el relacionante puede estar incorporado explícitamente, como en los casos anteriorcs (en-, so-, sub-), o pucde venir implicado de forma genérica, con lo que el localismo de la construcción queda en un segundo plano:

Zulacó el arcaduz / "puso zulaque en el arcaduz.
Zumacó la piel / "puso zumaque en la piel.
Zunchó la armadura / *puso zunchos é la armadura.

En aquellas construcciones en las que el verbo lleva incorporada la figura, y sólo la figura, quiero decir con ello que es necesario el complemento de lugar como tal, la incorporación puede conceptualizarse de forma local o factitiva, pero en cualquiera de los dos casos se hace necesario el complemento de lugar ${ }^{58}$ :

El limo se sedimentó en el fondo del mar / *hizollocalizó sedimento en el fondo del mar. La luz se reflejaba en el agua / thacialocalizaba reflejos en el agua.

Hay algún caso en el que la incorporación no es hecha sobre la figura exactamente, sino sobre un predicativo que incide en la figura, por lo que la incorporación no es de un sustantivo, sino de un adjetivo o participio:

\section{Fijo su residencia en Alicante: *hizo/puso fija su residencia en Alicante.}

Igual que ocurría con los procesos de amalgama de la base, son muchos los casos en los que la incorporación de la figura no es producto de una formación románica, sino latina (o a partir de otra lengua), así como también hay que considerar como habitual la posibilidad de que el significado del verbo formado por incorporación cambie y evolucionc de su significado originario:

Figuraba ${ }^{59}$ entre los candidatos / *localizaba/hacía su figura entre los candidatos > ampliación del significado.

Mora ${ }^{60}$ en palacio $/$ "hace mora en palacio > ampliación del significado.

57 En paralclo con cl apartado antcrior, y a pesar de que en este tipo resulte muchísimo más interesante la aparición del prefjo, vamos a seguir manteniendo también un único tipo de amalgama (figura), aunque, a veces, puedan, y deban, ser dos los elementos amalgamados, figura y trayectoria.

58 La conceptualización local y factitiva son los dos casos más habituales, pero también son posibles otros: veranea en Alicante: *pasa el verano en Alicante.

59 Del latín figurare, 'dar forma, representar', derivado de figura, -ae, 'configuración, estructura, imagen, forma, manera de ser' (Corominas y Pascual, 1984).

60 Del latín morari, 'detener, entretenerse, quedarse, permanecer' (Corominas y Pascual, 1984), derivado a su vez de mora, -ae, 'parada, pausa' (Ernout y Meillet, 1959). 


\subsubsection{Construcciones de acusativo partitivo}

En Cifuentes (1999) ya expusimos cómo las llamadas construcciones de acusativo partitivo pueden ser entendidas como incorporaciones conceptuales de la figura en un proceso de localización.

Las construcciones de acusativo partitivo son aquellas en las que verbos como golpear; herir, morder, pucden insertarse en dos tipos de estructuras, que responden a la siguiente esquematización según Cano Aguilar (1981: 63-65):

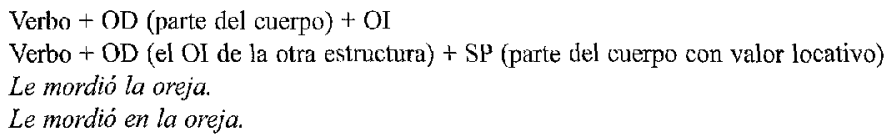

Se suele decir que en las estructuras directas se presupone quc lo mordido fue toda la oreja, mientras que la construcción con locativo presenta una interpretación "partitiva», lo mordido fue solo una parte.

Hasta ahora, las amalgamas o fusiones de la figura que habíamos venido considerando, eran producto de un desarrollo a partir de un sustantivo, que funcionaba como la figura implicada, tratándose, en definitiva, de verbos denominales construidos localmente mediante la incorporación conceptual señalada. Sin embargo, en las construcciones ahora objeto de comentario, aunque puede haber casos de verbos denominales, la mayoría no lo son, sino que, contrariamente, posibilitan un sustantivo derivado verbal (arañar-arañazo, herir-herida, vara-varear, zapato-zapatear).

Si consideramos la estructura local de estas construcciones, vemos que la expresión locativa Ubi nos especifica la base local y la relación de espacialización de la marca casual, sin embargo la figura y el tipo de predicación que se da es más complejo dcterminarlo. Todos estos verbos pueden ser parafraseados de forma analítica (golpear/dar un golpe, morder/dar un mordisco, etc.), siendo el objeto inherente la figura de la localización, es por ello que cuando vienen manifestados en forma sintética expresan un modo de acción. De esta forma, en las estructuras directas se predica una manera o modo de acción pero no se manifiesta una conceptualización local. Sin embargo, el conjunto de verbos que venimos considerando pueden manifestar una conceptualización local mediante la expresión del SP con en. Así pues, este tipo de verbos puede ser categorizado de dos mancras: cn cuanto manera de acción que afecta a un objeto, o en cuanto manera de acción que afecta a un lugar; la convertibilidad objeto/lugar explica la posibilidad de expresión de una u otra manera. Igualmente, que el objeto/lugar sea una parte del cuerpo humano es una característica determinantc. Cuando el modo de acción afecta a la consideración de un objeto, no es visto como relevante el objeto interno, necesario como figura para la localización.

En cuanto a la dualidad parte/todo, que tradicionalmente se ha venido considerando como la diferencia que permitía dislinguir una exprcsión directa de una locativa, es un aspecto deducible del razonamiento expuesto con anterioridad: en le mwerdo la pierna, la pierna es neutralizada en cuanto a su extensión o totalidad, ya que se considera al objeto en su conjunto como modificado por determinado modo de acción. Sin embargo, cn me mordió en la pierna, la conceptualización local implica «dar un mordisco en la pierna», y, evidentemente, depende del agente causante ( (hombre» o «tiburón», por cjemplo), que el mordisco 
se localicc en una extensión u otra de la pierna, pues ya no se trata del objeto afectado por la acción de «morder», sino de la localización de un «mordisco».

Los verbos de acusativo partitivo suponen la conceptualización de tres procesos bási$\cos ^{61}$ : a) factitivo: se trata de la realización de una acción en una parte del cuerpo: herir, quemar,arañar.

Lo/le hirió en la pierna (*le hizo una herida en la pierna) he hinó la pierna. Lo/le quemó en la mejilla (*le hizo una quemadura en la mejilla)/le quemó la mejilla. Lo/le arañó en el pecho (*le hizo un arañazo en el pecho)/e arañó el pecho.

Fijémonos en que la figura implicada es el resultado de la acción que realiza el sujeto, y son derivados los sustantivos del verbo de acción implicado. En español estas acciones se conciben como resultados factitivos por el hecho de que las paráfrasis siempre se haccn con el verbo hacer, no de otra manera, lo cual no quiere decir que en otra lengua no pueda hacerse de distinta forma, claro está.

b) Transferencia. Sc trata de un proceso por el cual el destinador le transfiere al destinatario, en el que se realiza la acción, un determinado suceso, haciéndole sentir los efectos de su acción. En español cstos verbos están formados normalmente a partir del sustantivo implicado como figura en la acción. Entiendo que estos verbos expresan un contenido de transferencia, porque pueden ser expresados los mismos contenidos analíticamente por medio de paráfrasis con dar: besar, golpear, morder, azotar.

Lo/le besó en la cara (*le dio un beso en la cara)/le besó la cara.

Lo/le golpeó en el higado (*le dio golpes en el higado)/le golpeó el higado.

Lo/le mordió en el centro (*le dio un modisco en el centroj/le mordió el centro.

Lo azotó en la espalda (*le dio azotes en la espalda)/le azotó la espalda.

$\mathrm{Al}$ igual que ocurría con los ejemplos anteriores, todos estos verbos, transitivos, normalmente requieren un destinatario animado, dc ahí que este hecho, junto con la idea de una figura como complemento directo implícito, contribuyan a que haya una cierta confusión con los pronombres implicados: lo/le, por ejemplo.

c) Localización instrumental. En este caso se trata de una acción en la que el agente se ayuda de un instrumento, que es el sustantivo que funciona como figura, y del que derivará el verbo, ocasionándole al destinatario un determinado efecto: varear, fustigar, zapatear. Estos verbos pueden posibilitar estructuras en las que la figura implicada pueda aparecer sintácticamente como especificación instrumental, pero únicamente en las construcciones no partitivas, lo que puede ser prueba de su presencia funcional en las estructuras partitivas: le vareó el trasero con la rama de un árboll?le vareó en el trasero con la rama de un árbol.

Lofle vareó en el trasero (*le dio con la vara en el trasero/*le puso la vara en el trasero)/le vareó el trasero.

Lafle fustigó en la espalda (*le dio con la fusta en la espalda*le puso la fusta en la espalda)/le fustigó la espalda.

La/le zapatéo en la cara (*le dío con los zapatos en la cara/le puso los zapatos en la cara) le zapateó la cara.

61 Pero en los tres concebimos que el complemento de lugar, cuando aparece, ticnen algún grado de obligatoriedad. 
En todos estos procesos está claro que alternan formaciones románicas y formaciones latinas, to que a veces contriburye a la dificultad de descripción.

El conjunto de verbos que posibilitan estas construcciones, aun siendo muy variado, puede reducirse a algunos subconjuntos, pues no olvidemos que tiene que tratarse de una interacción con alguna parte del cuerpo:

a) Verbos que implican algún tipo de golpe o caricia: acariciar, arañar, azolar, besar, besuquear, fustigar, golpear, herir, hurgar, morder, paporrear, pellizcar, pizcar, picar, picotear, pinchar, pisar, punzar, quemar, rascar, repizcar, varear, verberar, zapatear, zurrar.

b) Verbos que implican algún tipo de mancha, sea para ponerla o para quitarla: pintar, untar, manchar, ensuciar, limpiar.

c) Verbos vinculados con los sentidos en los que es posible concebir una figura en la acción: mirar (mirada), tocar, palpar, rozar (roce), oler, olfatear, olisquear (olor, o aspiración del mismo), chupar (chupetón).

Hay algunos verbos, como dar o pegar, que, quizás por influencia con los del grupo a), suponen estructuras parecidas a las anteriores, aunque sin posibilidad de construir la frase no partitiva:

Le pegó en la cara / *le pegó la cara.

Le dio en la cara / "le dio la cara.

Es claro que en los ejemplos válidos hay una figura implicada, un objeto inherente, que es un cierto tipo de golpc.

Un verbo como husmear quizás podría ser entendido como perteneciente al grupo c), en tanto que supone 'rastrear con el olfato', lo que podría explicar la dualidad constructiva siguicnte:

Husmeaba el terreno / husmeaba en el terreno.

Ahora bien, considero que el primitivo significado en el que quedaba implicado el contenido de olfato es poco rentablc, además de no tener conciencia los hablantes del hecho del olfato, al ser de origen griego la palabra, por lo que será mucho más usual el significado 'andar indagando con disimulo', extensión o ampliación de significado muy común a partir del significado original (Sanlos y Espinosa, 1996: 141-142). Es por ello que no creo probable que la doble posibilidad (transitiva e intransitiva) derive de su similitud con las construcciones de acusativo partitivo, sino de la analogía con verbos como indagar, fisgar, fisgonear, curiosear, huronear, que suponen un complemento de lugar con en (aparte de su relación paradigmática con mirar en $)^{62}$. Además, la construcción es distinta de las de acusativo partitivo, pues en esta ocasión no hay ninguna persona como complemento indirecto que pasa a complemento directo. Esta analogia nos permitiría también entender otros ejemplos similares, como hurgar.

62 La misma cxplicación cabría dar para un ejemplo como otear, pues desde su significado original vinculado etimológicamente con alto, 'mirar desde lo alto', ha perdido toda transparencia del mismo pasando a ser mucho más usual el significado derivado del anterior, y paradigmático con los que estamos considerando, 'escudriñar, registrar, mirar con cuidado". 


\subsection{Localización + relacionante}

Con esta amalgama Talmy (1985: 68-72) quiere señalar el esquema tipológico por el cual el verbo expresa tanto el hecho de la localización como la relación entre figura y base, y aunque los ejemplos que proporciona son de verbos de desplazamiento, es obvio que también son posibles con vcrbos estativos.

La mayoría de estos verbos, sean de formación románica o latina, están compuestos por un prefijo local que especifica la relación entre figura y base, o son resultado de un desatrrollo a partir de un elemento que funciona como relacionante local, igual que ocurría con los verbos de desplazamiento:
Antepuso el articulo al nombre: *puso el articulo delante del nombre.
Enfrentó la rueda a la pared: "puso la rueda enfrente de la pared.
Lo atrasó: *lo puso detrás (base dada contextualmente).
Centra el cuadro en la pared: *pon el cuadro en el centro de la pared.

Igual que ocurria con las anteriores fusiones, puede haber verbos que hayan evolucionado su significado desde la incorporación local que dio origen a la formación:

Subscribió la carta: *escribió debajo de la carta > extensión del significado.

Normalmente los verbos que llevan incorporado cl relacionante, al construirse con el complemento de hugar que funciona como base, llevan una preposición local genérica, como hemos visto en los ejemplos anteriores, pero pucde ocurrir perfectamente que el complemento de hugar localizante reitere el relacionante incorporado, pudiendo ser las razones para cllo muy varias: evolución del significado del verbo, pérdida de conciencia y de transparencia del valor del prefijo, etc.:

Debajo de la cama subyacia una sorpresa: "una sorpresa yacia debajo de la cama.

\section{CONCLUSIONES}

Creemos haber dejado asentada la estructura fundamental de la tipología de las construcciones locales estativas del español, que podemos resumir en el esquema siguiente, independientemente de su valor transitivo o intransitivo.

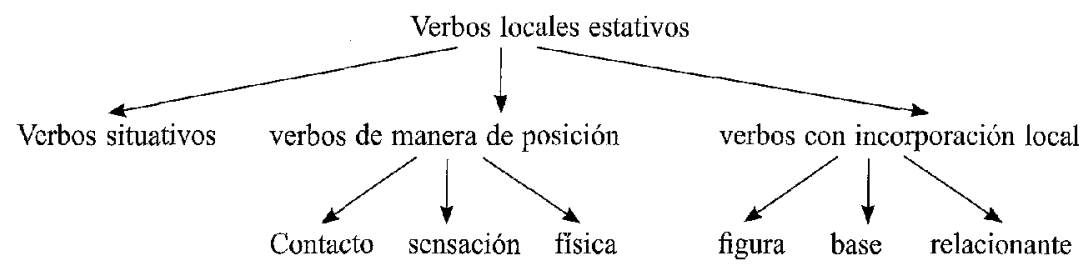

Quizás uno de los hechos más significativos pueda ser la semejanza con las construcciones de movimiento, tanto en lo referente a la organización transitiva e intransitiva, como en 
cuanto a las posibilidades de las incorporaciones conceptuales. Este último aspecto nos ha llamado mucho la atención, pues supone adentrarse en los procesos cognitivos que subyacen a la formación de palabras y, en definitiva, en las estructuras de pensamiento, dentro de las cuales, creo, los esquemas de localización tienen un lugar destacado.

\section{REFERENCIAS BIBI.IOGRÁFICAS:}

Alvar, M. y Pottier, B. (1982): Morfología histórica del español, Madrid: Gredus.

Arad, M. (2003): «Locality constraints on the interpretation of roots: the case of hebrew denominal verbs», Natural Langwage and Linguistic Theory, 21, págs. 727-778.

Asher, N. y Sablayrolles, P. (1995): «A lypology and discourse semantics for motion verbs and spatial Pps in French», Journal of Semantics, 12-2, págs. 163-209.

Austin, P. (1998): $\propto$ Crow is sitting chasing them»: Grammaticization and the verb «to sit» in the Mantharta languages, Western Australia», in A. Siewierska y J. J. Song (eds.): Case, Typology and Grammar, Amsterdam/Filadelfia: John Benjamins, págs. 19-35.

Baker, M. C. (1988): Incorporation. A theory of Grammatical Function Change, Chicago: University of Chicago Press.

Baker, M. C. (1996): The Polysynthesis Parameter, Oxford: OUP.

Berthele, R. (2003): «The typology of motion and posture verbs: A variationist account»,

Boons, J. P. - Guillet, A. - Leclère, C. (1976): La structure des phrases simples en français, Ginebra: Droz.

Cano Aguilar, R. (1981): Estructuras sintácticas transitivas del español actual, Madrid: Gredos.

Cifuentes Honrubia, J. L. (1989): Lengua y espacio. Introducción al problema de la deixis en español, Alicante: Universidad de Alicante.

Cifuentes IIonrubia, J. L. (1994): Gramática cognitiva. Fundamentos críticos, Madrid: Eudema.

Cifuentes IIonrubia, J. L. (1996): Usos prepositivos en español, Murcia: Universidad de Murcia.

Cifuentes Honrubia, J. L. (1999): Sintaxis y semántica del movimiento. Aspectos de grapnática cognitiva, Alicante: Instituto de Cultura 'Juan Gil Albert'.

Cifuentes Honrubia, J. L. y Llopis Ganga, J. (1996): Complemento indirecto y complemento de lugar. Estructuras locales de hase personal en español, Alicante: Universidad de Alicante.

Corominas, J. y Pascual, J. A. (1984): Diccionario critico-etimológico castellano e hispánico, Madrid: Gredos.

Crego García, M. V. (2000): El complemento locativo en español. Los verbos de movimiento y su combinatoria sintáctico-semántica, Santiago: Santiago de Compostela.

Cuenca, M. J. y Hilferty, J. (1999): Introducción a la lingüistica cogniliva, Barcelona: Ariel.

Demonte, V. (1991): «Tiempo y aspecto en los predicativos adjetivos», in V. Demonte: Detrás de la palabra, Madrid: Alianza, págs. 116-154.

Dervillez-Bastuji, J: (1982): Structures des relations spatiales dans quelques langues naturelles, Ginebra : Droz.

Di Sciullo, A. M y Williams, E. (1987): On the Definition of Word, Cambridgc: MIT Press.

Dik, S. C. (1980): Studies in Functional Grammar, Nueva York: Academic Press.

Ernout, A. y Meillet, A. (1959) : Dictionnaire étymologique de la langue latine. Histoire des mo/s, Paris: Klincksieck.

Farkas, D. F. y De Swart, H. (2003): The semantics of incorporation. From argument structure to discourse transparence, Stanford: CSII.

Fodor, J. y Lepore, E. (1997): «Morphemes matter: the continuing case against lexical decomposition (or: Please don't play that again, Sam)》, Ms., Rutgers University.

Gaylán, E. H. (1998): A Study of PATH: The Semantics of English and Spanish dynamic prepositions and motion and manner verbs, Tesis Doctoral, Chicago, Illinois. 
Gerdts, D. B. (1998): «Incorporation), in A. Spencer y A. M. Zwicky (eds.): The Handbook of Morphology, Oxford: Basil Blackwell, págs. 85-99.

Gibbs, R. W. Jr. - Beitel, D. A. - Harrington, M. y Sanders, P. E. (1994): «Taking a stand on the meanings of Stand: Bodily experience as motivation for polysemy», Joumal of Semantics, 11 , págs. 231-251.

Hale, K. y Keyser, S. J. (2002): Prolegomenon to a Theory of Argument Structure, Cambridge: The MIT Press.

Harley, H. (1999): «Denominal Verbs and Aktionsart», in L. Pylkkänen y A. van Ilout (eds.): Proceedins fo the $2^{\text {rut }}$ Penn/MT Roundtable on Event Structure, Cambridgc, Massachussets, 13 págs.

IIarley, H. (2001): «How do verbs get their names? The Aktionsart of denominal verbs and the ontology of verb roots in English», Ms., University of Arizona.

Horno Chéliz, M. C. (2002): Lo que la preposición esconde, Zaragoza: PU7.

Jackendoff, R. (1990): Semantic Structures, Cambridge: The MIT Press.

Jelinek, E. (1984): «Empty catcgories, case, and configurationality», Natural Language and Linguistic Theory, 2, págs, 39-76.

Kiparsky, P. (1997): «Remarks on Denominal Vcrbs», in A. Alsina, J. Bresnan y P. Sells (eds.): Complex Predicates, Santaford: CSLI, págs. 473-499.

Kirschner, C. (1981): Semántica generativa del español, Salamanca: Almar.

Kracht, M. (2003): «Directionality selection», ms., págs. 1-13.

Kuteva, T. A. (1999): «On «sit»/ «stand» / «lie» auxiliation», Linguistics, 37, págs. 191-213.

Labclic, M. (2000): «The Semantic Representation of Denominal Verbs», in P. Coopmans - M. Everaert y J. Grimshaw (eds.): Lexical specification and insertion, Amsterdam: John Benjamins, págs. $215-240$.

Lamiroy, B. (1991): Léxico y gramática del español, Barcelona: Anthropos.

Langacker, R. W. (2004): «l'osesión, Location, and Existente», in A. Soares da Silva - A torres y M. Gonçalves (eds.): Linguagem, cultura e cognição. Estudos de lingüistica cognitiva, Coimbra: Almedina.

Lazard, G. (1984): «Actance Variations and Categories of the Object», in F. Plank (ed.): Objects. Towards a theory of grammatical relations, Londres: Academic Press, págs. 260-292.

Lemmens, M. (2002): 《The semantic network of Dutch zitten, staan, and liggen», in J. Newman (cd.), págs. 103-139.

Malouf, R. (1999): "West Grecnlandic noun incorporation in a monohierarchical theory of grammar", in G. Webelhuth $-\Lambda$. Kathol y J.P. Koenig (cds.): Lexical and Constructional Aspects of Linguistic: Explanation, Stan「ord: CSLI, págs: 47-62.

Marantz, A. (1984): On the nature of grammatical relations, Cambridge: MIT Press.

Mardirussian, G. (1975): «Noun-Incorporation in Universal Grammar», Papers from the $11^{\text {th }}$ Regional Meeting, Chicago: Chicago Linguistic Society, págs. 383-389.

Maten i Fontanals, J. (2001a): «Locative and locatum verbs revisited. Evidence from Romance», in Y. d'Hulst - J. Rooryck y J. Schroten (eds.): Romance Languages and Linguistic Theory 1999, Amsterdam: John Benjamins, págs. 223-244.

Mateu i Fontanals, J. (2001b): «Preverbs in complex denominal verbs: lexical adjuncts or core predicates?», Catalan Working Papers in Linguistics, 9, págs. 37-51.

Mateu i Fontanals, J. (2002): Argument structure: relational construal at the syntax-semantics interface, Tesis Doctoral, Universidad Autónoma de Barcelona.

Miller, G. A. y Johnson-Laird, P. N. (1976): Iuanguage and Perception, Massachussets: Harvard University Press.

Mithun, M. (1984): «The evolution of noun incorporation», Language, 60-4, págs. 510-546.

Mithun, M. (2000): «Incorporation», in G. Booij - C. Lehmann - J. Mugdan - W. Kesselheim y S. Skopeteas (eds.): Morphologie/Morphology, 1, Berlín-Nueva York: Walter de Gruyter, págs. 916 928. 
Montoro Montalbán, R. M. y Cifuentes Honrubia, J. L. (1996): «Relaciones cognitivas de doble proceso en verbos parasintéticos», Pragmalingü̈istica, 3-4, págs. 659-668.

Moreno Cabrera, J. C. (1991): Curso universitario de lingüistica general, Madrid: Sintesis.

Moreno Quibén, M. y Romero Morales, J. (2000): «On the syntax of Locatio and Locatum Verbs», Cuadernos de Lingüistica del 1.U. Ortega y Gasset, VII, págs. 145-155.

Morimoto, Y. (2001): Los verbos de movimiento, Madrid: Visor.

Nansen Díaz, E. (2000): «Las lenguas que forman cuerpo con el verbo. Apuntes para la historia del término incorporación i, págs. 263-272.

Newman, J. (2001): «A corpus-based study of the figure and ground in sitting, standing, and lying constructions's, Studia Anglica Posnaniensia, 36, págs. 203-216.

Newman, J. (ed.) (2002): The Lingusitics of Sitting, Standing, and Lying, Amsterdam \& Philadelphia: John Benjamins.

Newman, J. y Rice, S. (2001): "English ST, STAND, and LIE in small and large corpora", The ICAME Journal, 25, págs. 109-133.

Newman, J. y Rice, S. (2004): "Patterns of usage for English sIT, STAND, and LIE: A cognitively-inspired exploration in corpus linguistics», Cognitive Linguistics, 15-3, págs. 351-396.

Parisi, G. y Castelfranchi, C. (1979): «Analisi semántica dei locativi spaciali», La sintáis, Roma: Bulzoni.

Piera, C. y Varela, S. (1999): «Relaciones entre morfologia y sintaxis», in I. Bosque y V. Demonte (coords.): Gramática descriptiva de la lengua española, Madrid: Espasa-Calpe, págs. 4367-4422.

Pullum, G. (1996): «Nostalgic views from MIT. Review article on The Iiew from Building 20: Essays in Linguistics in Honor of Sylvain Bromberger, ed. by K. Hale and S. J. Keyserm, Journal of Linguistics, 32, págs. 137-147.

Ramón Trives, E. (1990): «El estudio de la lengua en los tipos sintagmáticos latentes propiciados por los verbos locativos y los tipos semióticos pragma-lingüísticos oracionales o manifestativos), in Homenaje al Prof. Juon Barceló Jiménez, Murcia: Academia 'Alfonso X el Sabio', págs. 547575.

Ramón Trives, E. (2001): «El «tipo sintagmático latente» aplicable a los verbos «locativos» y construcciones predicativo-verbales «localizables» en español y en francés a la luz de la noemática hogcriana), in G. Wotjak (ed.): Studien zum romanisch-deutschen und innerromanischen Sprachvergleich, Frankfurt: Peter Lang, págs. 105-111.

Rappaport, M. y Levin, B. (1988): «What to Do UIT Theta Roles», in W. Wilkins (ed.): Syntax and Semantics. Vol. 21: Thematic Relations, San Diego: Academic Press.

Roegiest, E. (1980): Les prépositions «a» et «de» en espagnol contemporain, Gante.

Rosen, S. T. (1989): «Two types of Noun Incorporation», Language, 65, págs. 294-317.

Sadock, J. M. (1980): «Noun Incorporation in Greenlandic : A Case of Syntactic Word-Formation», Language, 57, págs. 300-319.

Sadock, J. M. (1991): Autolexical Syntax. A Theory of Parallel Grammatical Representations, Chicago: The University of Chicago Press.

Santiago Lacuesta, R. y Bustos Gisbert, E. (1999): «La derivación nominal», in I. Bosque y V. Demonte (coords.): Gramática descriptiva de la lengua española, Madrid: Espasa-Calpe, págs. 4505-4594.

Santos Domínguez, L. y Espinosa Elorza, R. (1996): Mamal de semántica histórica, Madrid: Síntesis.

Schulze, R. (1987): «The Perception of Space and the Function of Prepositions in English: A Contribution to Cognitive Grammary, in W. Lörscher * R. Schulze (eds.): Perspectives on Language in Performance, Tubinga: Gunter Narr.

Serra Borneto, C. (1996): «Liegen and stehen in German: A study in horizontality and verticality», in E. H. Casad (ed.): Cognitive Linguistics in the Redwoods: The Expansion of a New Paradigm in Linguistics, Rerlin y Nueva York: Mouton de Gruyter, págs. 459-505. 
Serrano Dolader, D. (1995): Las formaciones parasintéticas en español, Madrid: Arco/Libros.

Serrano Dolader, D. (1999): «La derivación verbal y la parasíntesis», in I. Bosque y V. Demonte (coords.): Gramática descriptiva de la lengua española, Madrid: Espasa-Calpe, págs. 4683- 4755.

Strawson, P. F. (1959): Individuals, Londres: Mehuen.

Svorou, S. (1993): The Grammar of Space, Amsterdam-Philadelphia: John Benjamins.

Talmy, L. (1975): «Semantics and syntax of motion», in J. Kimball (ed.): Syntax and Semantics, 4, Nueva York: Academic Prcss, págs. 181-238.

Talmy, L. (1983): «How languages structures space», in H. L. Pick y L. P. Acredolo (cds.): Spatial Orientation, Nueva York: Plenum Press, págs. 225-282.

Talmy, L. (1985): «Lexicalization patterns: semantic structure in lexical forms», in T. Shopen (ed.): Language typology and syntactic descriptions, Nueva York: Cambridge University Press, págs. $57-149$.

Talmy, L. (2000): Toward a Cognitive Semantics, II, Cambridge: The MIT Press.

Val Alvaro, J. F. (1999): «La composición», in I. Bosque y V. Demonte (coords.): Gramática descriptiva de la lengua española, Madrid: Espasa-Calpe, págs. 4757-4841.

Van Geenhoven, V. (1998): Semanitic incorporation and inde/inite descriptions, Stanford: CSLI.

Van Oosten, J. (1982): «Sitting, standing, and lying in Dutch: A cognitive approach to the distribution of the verbs zitten, staan, and liggens, in J. van Oosten y J. P. Snapper (eds.): Dutch Linguistics at Berkeley, Berkeley: University of California at Berkeley, págs. 137-I61.

Vandeloise, C. (1986): L'espace en français, París: Seuil.

Varela, S. y Martín García, I. (1999): «La prefijación», in I. Bosque y V. Demonte (coords.): Gramática descriptiva de la lengua española, Madrid: Espasa-Calpe, págs. 4993-5040.

Vera Luján, A. (1987): Aspectos sintáctico-semánticos en la sufjjación, Murcia: Universidad de Murcia.

Vera Luján, A. (1994): «Sobre el estatuto lingüístico-funcional de los casos scmánticos: agente, fuerza e instrumento», LEA, XVI-2, págs. 137-156.

Von Heusinger, K. y Schwarze, C. (2002): «Underspecification in the semantics of word-formation. The case of denominal verbs of removal in Italian", Arbeitspapier 111, Fachbereich Sprachwissenschaft Universität Konstanz.

Wotjak, B. (1990): «Acerca de incorporaciones lexcmáticas en verbos españoles», in G. Wotjak y A. Veiga (coords.): La descripción del verbo español, Santiago: Universidad de Santiago de Compostela, págs. 259-264. 